\title{
Coordinated analyses of Antarctic sediments as Mars analog materials using reflectance spectroscopy and current flight-like instruments for CheMin, SAM and MOMA
}

\author{
Janice L. Bishop ${ }^{\mathrm{a}, \mathrm{b}, *}$, Heather B. Franz ${ }^{\mathrm{c}, \mathrm{d}}$, Walter Goetz ${ }^{\mathrm{e}}$, David F. Blake ${ }^{\mathrm{b}}$, Caroline Freissinet ${ }^{\mathrm{c}, \mathrm{d}}$, \\ Harald Steininger $^{\mathrm{e}}$, Fred Goesmann ${ }^{\mathrm{e}}$, William B. Brinckerhoff ${ }^{\mathrm{c}}$, Stephanie Getty ${ }^{\mathrm{c}}$, Veronica T. Pinnick ${ }^{\mathrm{c}, \mathrm{d}}$, \\ Paul R. Mahaffy ${ }^{\mathrm{c}}$, M. Darby Dyar ${ }^{\mathrm{f}}$ \\ a Carl Sagan Center, The SETI Institute, Mountain View, CA 94043, USA \\ ${ }^{\mathrm{b}}$ Exobiology Branch, NASA-Ames Research Center, Moffett Field, CA 94035, USA \\ c Planetary Environments Laboratory, NASA Goddard Space Flight Center, Greenbelt, MD 20771, USA \\ ${ }^{\mathrm{d}}$ Center for Research and Exploration in Space Science E Technology, University of Maryland, Baltimore, MD 21250, USA \\ ${ }^{\mathrm{e}}$ Max-Planck-Institut für Sonnensystemforschung, Katlenburg-Lindau D-37191, Germany \\ ${ }^{\mathrm{f}}$ Department of Astronomy, Mount Holyoke College, South Hadley, MA 01075, USA
}

\section{A R T I C L E I N F O}

\section{Article history:}

Available online $\mathrm{xxxx}$

\section{Keywords:}

Mars, surface

Mineralogy

Organic chemistry

Spectroscopy

\begin{abstract}
A B S T R A C T
Coordinated analyses of mineralogy and chemistry of sediments from the Antarctic Dry Valleys illustrate how data obtained using flight-ready technology of current NASA and ESA missions can be combined for greater understanding of the samples. Mineralogy was measured by X-ray diffraction (XRD) and visible/ near-infrared (VNIR) reflectance spectroscopy. Chemical analyses utilized a quadrupole mass spectrometer (QMS) to perform pyrolysis-evolved gas analysis (EGA) and gas chromatography-mass spectrometry (GC/MS) both with and without derivatization, as well as laser desorption-mass spectrometry (LD/MS) techniques. These analyses are designed to demonstrate some of the capabilities of near-term landed Mars missions, to provide ground truthing of VNIR reflectance data acquired from orbit by the Compact Reconnaissance Imaging Spectrometer for Mars (CRISM) on MRO and to provide detection limits for surface-operated instruments: the Chemistry and Mineralogy (CheMin) and Sample Analysis at Mars (SAM) instrument suites onboard Mars Science Laboratory (MSL) and the Mars Organic Molecule Analyzer (MOMA) onboard ExoMars-2018. The new data from this study are compared with previous analyses of the sediments performed with other techniques. Tremolite was found in the oxic region samples for the first time using the CheMin-like XRD instrument. The NIR spectral features of tremolite are consistent with those observed in these samples. Although the tremolite bands are weak in spectra of these samples, spectral features near 2.32 and $2.39 \mu \mathrm{m}$ could be detected by CRISM if tremolite is present on the martian surface. Allophane was found to be a good match to weak NIR features at $\sim 1.37-1.41,1.92$, and $2.19 \mu \mathrm{m}$ in spectra of the oxic region sediments and is a common component of immature volcanic soils. Biogenic methane was found to be associated with calcite in the oxic region samples by the SAM/EGA instrument and a phosphoric acid derivative was found in the anoxic region sample using the SAM/MTBSTFA technique.
\end{abstract}

(c) 2012 Elsevier Inc. All rights reserved.

\section{Background}

The objective of this study is to investigate some wellcharacterized samples with instrumental techniques that are (or will be) available on the Mars Science Laboratory (MSL) and ExoMars-2018 science payload, and visible/near-infrared (VNIR) reflectance spectroscopy in order to support coordination of the data from upcoming surface missions with the mineralogy

\footnotetext{
* Corresponding author.

E-mail address: jbishop@seti.org (J.L. Bishop).
}

observed by current orbital spectrometers. The Observatoire pour la Minéralogie, l'Eau, les Glaces et l'Activité (OMEGA) on Mars Express collects data from 0.4 to $5.2 \mu \mathrm{m}$ at a spatial resolution of hundreds of meters and documented the first conclusive evidence of phyllosilicates and sulfates on the surface of Mars (Bibring et al., 2005; Gendrin et al., 2005; Poulet et al., 2005). The Compact Reconnaissance Imaging Spectrometer for Mars (CRISM) collects data from 0.4 to $3.9 \mu \mathrm{m}$ at $7 \mathrm{~nm}$ spectral intervals and $18 \mathrm{~m} /$ pixel spatial resolution for $\sim 12 \mathrm{~km}$ wide swaths (Murchie et al., 2009b). Analyses of CRISM data have revealed multiple types of aqueous systems across Mars (Murchie et al., 2009a). Gale crater, the 
destination of MSL, contains both phyllosilicates and sulfates that have been identified from orbit (Milliken et al., 2010). The ancient mound deposits are considered to be sedimentary (Grotzinger et al., 2011) and may have other aqueous minerals such as carbonates.

\subsection{Antarctic Dry Valleys}

Soils and sediments from the Antarctic Dry Valleys (Fig. 1) have long been under study as potential analogs for surface processes on Mars (Gibson et al., 1983; McKay et al., 1985; Wharton et al., 1989; Doran et al., 1998). Chemical weathering in the cold, arid environment of the Dry Valleys occurs at a slower rate compared to other locations on Earth, but still results in complex chemical weathering and may mimic some past martian environments (Gibson et al., 1983). Three separate zones are described in this extremely dry environment: subxerous environments that can support liquid water down to $\sim 1 \mathrm{~m}$, xerous soils that can support liquid water down to $\sim 50-100 \mathrm{~cm}$, and ultraxerous regions that cannot support liquid water in the soil (Campbell and Claridge, 1987; Gooseff et al., 2002; Blecker et al., 2006; Tamppari et al., 2012). Xerous zones are the most widespread in the Dry Valleys and occur in inland regions (Campbell and Claridge, 1987; Tamppari et al., 2012).

Geochemical analyses performed on soil samples from a $1 \mathrm{~m}$ deep pit in a subxerous region at Wright Valley near Lake Vanda found the permanently frozen zone at a depth of $\sim 40 \mathrm{~cm}$ (Gibson et al., 1983), consistent with other subxerous regions in the Dry Valleys (Campbell and Claridge, 1987; Marchant and Head, 2007). The Gibson et al. (1983) study noted higher salt concentrations $\sim 2-4 \mathrm{~cm}$ below the soil surface than at depth. This is attributed to migration of brines with increasing salt precipitation upward through the soil column (Wentworth et al., 2005). Thin films of liquid water are present along the boundaries of mineral

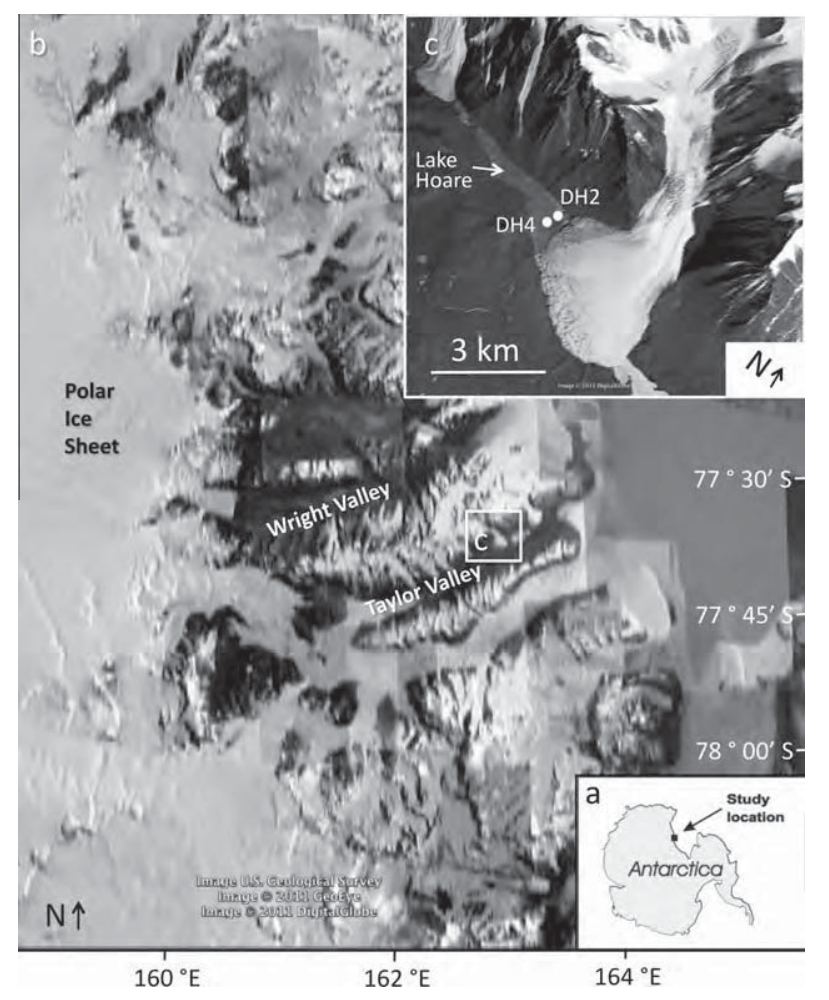

Fig. 1. Map of the Antarctic Dry Valleys (a, study location) indicating the location of the Taylor Valley (b) and Lake Hoare (c). Sediment cores were collected from dive holes (DH) 2 and 4. Image credits: US Geologic Survey, GeoEye, Digital Globe and Google. and ice grains even at temperatures much below freezing (Anderson, 1981). The abundance of secondary minerals (e.g. clays, zeolites and silica) correlates with the water soluble ion concentrations and may indicate that chemical alteration of soils is occurring today in subxerous regions of the Dry Valleys where water activity is present. A more recent study of soils in the Beacon Valley observed a clay fraction $(<2 \mu \mathrm{m})$ below $3 \%$ in most soils with elevated levels associated with higher salt content (Mahaney et al., 2009), consistent with values observed by Gibson et al. (1983).

A recent study of doleritic rock (e.g. mafic igneous rock with grain size intermediate between basalt and gabbro) and soil samples in Beacon Valley (Salvatore et al., 2010) found evidence of alteration rinds on rock surfaces. Elevated alteration levels on $\mathrm{N}-$ facing slopes and decreased alteration on S-facing slopes are attributed to wind scour removal of rinds on S-facing slopes. Another possibility is that more water activity is present on $\mathrm{N}$-facing slopes, promoting more alteration. Salvatore et al. (2010) found spectral features near $1.4,1.9$ and $2.2 \mu \mathrm{m}$ in a doleritic soil that are consistent with the presence of Al-phyllosilicates. They also observed an increase in spectral brightness across the $0.5-2.5 \mu \mathrm{m}$ region for altered samples compared to less altered ones.

Another interesting feature of the Dry Valleys region is the presence of ice-covered lakes that provide unique study environments for life in extreme aqueous habitats (McKay et al., 1985; Wharton et al., 1989; Doran et al., 1998; Fairén et al., 2010). Organisms exist in microbial mats in the lake bottom sediments below both oxic and anoxic regions of several perennially ice-covered lakes. Lake Hoare in the Taylor Valley (Fig. 1) features an oxygen-rich (oxic) zone above $\sim 27 \mathrm{~m}$ lake depth and an oxygen-poor (anoxic) zone below $\sim 27 \mathrm{~m}$ (Wharton et al., 1987, 1993; Andersen et al., 1998). Lake Hoare has received abundant attention due to the 3-5 m thick year-round ice cover and algal mats growing in both oxic and anoxic regions of the lake bottom (e.g., Nedell et al., 1987; Squyres et al., 1991; Doran et al., 1994, 2002; Spaulding et al., 1997).

The water temperature in Lake Hoare varies from 0.0 to $0.8^{\circ} \mathrm{C}$ (Spigel and Priscu, 1998), while the mean annual air temperature above the ice is typically $-18^{\circ} \mathrm{C}$ (Doran et al., 2002b). The pH of Lake Hoare was measured at 7.1 in anoxic regions at 27 and $29 \mathrm{~m}$ depth and increased gradually upward through the oxic waters to 8.8 at a depth of $3 \mathrm{~m}$ (Green et al., 1988). Ca precipitation as calcite is a dominant process in the oxic regions of the lake (Green et al., 1988; Neumann et al., 2001). Hawes and Schwarz (1999) found that this process occurs to a greater extent at $13 \mathrm{~m}$ or shallower depth. Benthic and planktonic microflora thrive in the Lake Hoare ecosystem despite the low solar radiation flux, near-freezing temperatures, and highly oxygenated environment (Wharton et al., 1983, 1987). Calculations of the $\mathrm{O}_{2}, \mathrm{~N}_{2}$ and $\mathrm{Ar}$ gases in the lake water and ice layer covering the lake show that $11 \%$ of the $\mathrm{O}_{2}$ input to Lake Hoare is due to photosynthetic activity in the lake and that $40-70 \%$ of this photosynthetic $\mathrm{O}_{2}$ is removed through the gas bubbles rising upward through the ice layer (Craig et al., 1992). The primary means of deposition of lake bottom sediment in Lake Hoare is transport through the surface ice (Nedell et al., 1987; Squyres et al., 1991).

Coordinated reflectance spectroscopy and geochemical analyses of lake bottom sediments from the Dry Valleys have enabled identification of minerals formed in this environment and characterization of microbial activity (Bishop et al., 1996, 2001). These studies analyzed numerous sediments retrieved from oxic and anoxic zones in Lake Hoare. Calcite and organic matter were abundant in oxic region lake bottom sediments (Bishop et al., 1996). Spectroscopic parameters were developed to discriminate the organic $C$ and calcite in these sediments, as the features for these groups both occur in the 3.3-3.5 $\mu \mathrm{m}$ spectral region. The mineralogy of the Lake Hoare sediments is dominated by quartz, feldspar, and 
pyroxene (Bishop et al., 1996), consistent with the rocks and soils from the Dry Valleys region (Campbell and Claridge, 1987).

Reflectance and Mössbauer spectroscopy were coordinated in order to characterize the Fe-bearing mineralogy in more detail (Bishop et al., 2001). This enabled measurement of the relative abundances of $\mathrm{Fe}^{2+}$ silicates such as pyroxene with $\mathrm{Fe}^{3+}$ alteration products such as clays and oxides. Modeling of the $77 \mathrm{~K}$ Mössbauer spectra enabled identification of two forms of pyroxene plus pyrite using pyroxene parameters defined by McCammon (1995). Isotopic signatures showed that this pyrite was formed biogenically from sulfate (Bishop et al., 2001). Variations in the $C$ and $N$ isotope patterns in the anoxic sediments are consistent with active biological cycling and changes in nutrient balances over time, whereas the $\mathrm{C}$ and $\mathrm{N}$ isotope patterns in the oxic sediments indicated relatively stable and unchanging conditions (Bishop et al., 2001). The Bishop et al. (2003) study involved Raman and reflectance spectra of coarse sediment grains and additional isotopic measurements. The abundance of pyrite, chlorophyll-like spectral absorptions, and organic $C$ were observed to correlate well with the $S$ isotope compositions in anoxic sediments, and microbial activity was found to be much higher in the anoxic sediments than in the oxic sediments. Raman analyses of sediment grains showed the presence of chalcedony together with quartz in some sediments (Edwards et al., 2004). Raman analyses of feldspar grains in that study found spectra consistent with a range of compositions including sanidine, oligoclase, albite, and labradorite, and found pyroxene grains corresponding to orthopyroxene and clinopyroxene. Selected magnetic grains were found to contain titanomagnetite (Bishop et al., 2003; Edwards et al., 2004).

\subsection{MSL - CheMin}

CheMin is a combination X-ray diffraction (XRD) and X-ray fluorescence (XRF) instrument on MSL that will provide mineralogical information about martian soils and rock powders (Blake et al., 2012). CheMin operates across an angular range of 5 to $50^{\circ} 2 \theta$ with $<0.35^{\circ} 2 \theta$ resolution and will typically acquire data over an integration time of $10 \mathrm{~h}$. The XRD component is equipped with internal chemical and mineralogical standards and 27 reusable sample cells. Techniques for accurate mineralogical identifications and quantitative phase abundances for the martian samples have been established using lab and field tests. CheMin is designed to achieve a relative accuracy of $15 \%$ and a relative precision of $10 \%$.

\section{3. $M S L-S A M$}

The Sample Analysis at Mars (SAM) instrument suite, the largest science payload on the Mars Science Laboratory (MSL) "Curiosity" rover, will perform chemical and isotopic analysis of volatile compounds from atmospheric and solid samples to address questions pertaining to habitability and geochemical processes on Mars (Mahaffy et al., 2012). The SAM analytical components include a quadrupole mass spectrometer (QMS), two pyrolysis ovens that can be used to heat each of 74 sample cups, six gas chromatograph (GC) columns, and a tunable laser spectrometer (TLS). Volatiles may be introduced into the QMS and TLS either directly from the atmosphere or by heating solid samples acquired at the martian surface in the pyrolysis ovens. Gases evolved from samples heated in the ovens may be conducted directly to the QMS or passed through one of the GC columns first. Nine pyrolysis cups onboard SAM are devoted to "wet chemistry," in which a derivatization agent is added to the solid sample before heating to produce a chemical transformation of organic compounds in the sample before analysis.

Several laboratory instrument test stands have been developed to allow modeling of various SAM subsystems without subjecting the flight unit to unnecessary contamination or depleting its consumable resources (Mahaffy et al., 2012). The highest fidelity QMS test stand, known as the SAM breadboard, utilizes a mass spectrometer nearly identical to that of the SAM flight model, controlled by a high fidelity RF electronics circuit and CPU that are both flight unit prototypes. GC breadboards include several commercial instruments that utilize columns identical or similar to those on the SAM flight model, with injection traps of the SAM design.

In the case of very fragile (easily degradable by pyrolysis) or refractory molecules, which cannot be analyzed by heating, a spaceflight-compatible chemical derivatization reaction will also be performed (Rosenbauer et al., 1999). For example, it has been shown (Glavin and Bada, 1998) that amino acids require chemical extraction from the solid mineral matrix prior to pyrolysis heating to avoid such decomposition. One of the derivatization solvents used in SAM, MTBSTFA, can transform less labile polar organic compounds, such as amino acids and carboxylic acids, into volatile tert-butyldimethylsilyl (tBDMS) derivatives that can be separated and identified by GC/MS. This valuable capability will also be included on the ExoMars MOMA instrument. In addition to the MTBSTFA derivatization, a single-step extraction and chemical derivatization protocol has been developed for MOMA using the dimethylformamide-dimethylacetal (DMF-DMA) derivatization reagent. This technique allows derivatization with conservation of enantiomeric centers of the molecules, enabling the chiral analysis of a wide range of exobiology-relevant refractory organic molecules (Freissinet et al., 2010). DMF-DMA derivatization is also included on the COSAC experiment onboard the Rosetta lander, expected to arrive at comet $67 \mathrm{P} /$ Churyumov-Gerasimenko in 2014 (Goesmann et al., 2007).

\subsection{MSL - ChemCam LIBS}

The Chemistry and Camera (ChemCam) Laser-Induced Breakdown Spectroscopy (LIBS) instrument on MSL will measure elemental abundances of rocks at a distance up to $\sim 7 \mathrm{~m}$ using laser pulses of $\sim 14 \mathrm{~mJ}$ (Wiens and Maurice, 2011). LIBS measures many elements simultaneously and can remove surface coatings through continued laser pulses on one site. LIBS instruments have the capability to quantify the abundance of important elements in sediments, such as H (Cremers et al., 2012), C (Martin et al., 2003, 2010), and S (Dyar et al., 2011) as well as most elements on the periodic chart up to $\mathrm{Pb}$ (Clegg et al., 2009; Tucker et al., 2010). Moreover, LIBS has the capability of fingerprinting organic molecules (Bricklemyer et al., 2011; Lasheras et al., 2011).

\subsection{ExoMars-2018 - MOMA}

The Mars Organic Molecule Analyzer (MOMA, Goetz et al., 2011) will be part of the Pasteur payload onboard the ExoMars-2018 rover and includes ovens for single use, a GC with four different column types, a pulsed ultraviolet (UV) laser for solid sample desorption and ionization, and a mass spectrometer (MS, designed as 2D ion trap). MOMA has two fundamentally different operational modes: (a) pyrolysis-GC/MS and (b) Laser Desorption and Ionization (LDI). The ExoMars-2018 rover will be able to collect subsurface samples from multiple depths (up to $2 \mathrm{~m}$ below the surface). Using mode (a) a given subsurface sample will be heated in a MOMA oven up to $\sim 1000^{\circ} \mathrm{C}$ and the released volatiles will be analyzed by the MS only (Evolved Gas Analysis) or by GC/MS. This mode is similar to procedures used for SAM, despite significant differences in design and hardware. Using mode (b) the sample-under ambient Mars conditions-will be interrogated by UV laser pulses whereby molecular (organic and/or inorganic) fragments are vaporized and transported via an ion guide into the 
low-pressure zone of the MS. In addition, mode (b) will return data with high spatial resolution $(\sim 400 \mu \mathrm{m}$, which is the anticipated diameter of the laser beam at the sample) and might reveal the distribution of organics among different types of (sand-sized) grains.

Currently flight-like MOMA subsystems exist, but no overall breadboard is currently available. Therefore commercial LDI and pyrolysis-GC/MS setups have been used to explore the synergy between both MOMA procedures.

\subsection{ExoMars-2018 - Raman}

The Raman instrument planned for ExoMars (Tarcea et al., 2008; Rull et al., 2011) will identify minerals and organic compounds. The Raman Laser Spectrometer (RLS) employs an excitational wavelength of $532 \mathrm{~nm}$ for surface spots $\sim 50 \mu \mathrm{m}$ across (Rull et al., 2011). Raman is useful for mineral identification and quantification of relative abundances (e.g. Haskin et al., 1997; Sharma et al., 2003, 2011; Rull et al., 2004) and has been successfully applied to studies of sediments from Antarctica (e.g. Edwards et al., 1997, 2004; Wynn-Williams and Edwards, 2000). Raman spectroscopy can also determine individual mineral composition, such as the distinction between fayalite and forsterite within the olivine solid solution (Kolesov and Tanskaya, 1996; Mouri and Enami, 2008) and low and high Ca pyroxenes (e.g. Edwards et al., 2004).

\section{Methods}

\subsection{Samples}

The frozen sediment cores were thawed and sample segments along the cores were separated by color, texture and obvious changes in mineralogy and organic components for a previous study (Bishop et al., 2001). The samples were then ground and dry sieved to $<125 \mu \mathrm{m}$ particle size. Samples E2, E3 and E4 are lake bottom sediments from an oxic region of Lake Hoare collected at dive hole 2 (DH2). Samples E2, E3 and E4 were sediments sectioned from 0.5 to 3,3 to 5 and 5 to $16 \mathrm{~cm}$ deep, respectively. Note that sample E3 was not originally planned for this study, but was added for the SAM GC/MS experiments only in order to provide additional information about the organic compounds in the oxic region sediments as it has extremely high abundances of calcite and organics (Tables 1 and 2). Sample H3 is a lake bottom sediment from a dee- per, anoxic region of the lake at dive hole 4 (DH4). Sample H3 was the section of the sediment core from 7 to $13 \mathrm{~cm}$ deep. Locations of the dive holes are shown in Fig. 1c. Selected elemental abundances from Bishop et al. (2001) for the samples studied here are shown in Table 1. Similarly, the isotope patterns and carbon abundances measured previously (Bishop et al., 2003) are given in Table 2 for comparison with the current results.

\subsection{X-ray diffraction}

X-ray diffraction (XRD) measurements were performed on the particulate Antarctic sediments in the lab using a CheMin-like instrument. Data were collected from 5 to $54^{\circ} 2 \theta$ and compared to known patterns of laboratory standards. Quantitative analyses of the data were performed using the Rietveld refinement method (Bish and Post, 1993). Crystalline minerals present above 1 wt.\% can generally be identified to within $\pm 5 \%$ accuracy based on previous analyses (e.g. Bish and Post, 1993; Hillier, 2000; Oladipo et al., 2006).

\subsection{Reflectance spectroscopy}

Reflectance spectra were measured for particulate samples in a horizontal sample dish using a bi-directional visible/near-infrared (VNIR) spectrometer and a Nicolet FTIR spectrometer at RELAB as in past studies (Bishop et al., 2001). Spectra were measured relative to Halon from 0.3 to $2.6 \mu \mathrm{m}$ under ambient conditions with $5 \mathrm{~nm}$ spectral sampling. Infrared reflectance spectra were measured relative to a rough gold surface in a biconical configuration with $2 \mathrm{~cm}^{-1}$ spectral sampling from $1-25 \mu \mathrm{m}$ in an environment purged of $\mathrm{H}_{2} \mathrm{O}$ and $\mathrm{CO}_{2}$ for $10-12 \mathrm{~h}$. Composite, absolute reflectance spectra were prepared by scaling the FTIR data to the bidirectional data near $1.2 \mu \mathrm{m}$. Spectra over the wavelength range $0.3-$ $4.4 \mu \mathrm{m}$ are included in this study.

\subsection{Evolved gas analysis}

In evolved gas analysis (EGA) experiments, powdered solid samples were heated in a quartz cup inside one of SAM's pyrolysis ovens, and the resulting gases were sampled directly by the QMS without passing through a GC column. This is the simplest type of experiment that SAM will perform with solid samples, yielding clues pertaining to mineralogy and the presence of organics. The experiments described here were performed with the SAM breadboard, using the same temperature profile, pressure and gas flow

Table 1

Selected major elements and LOI (in wt.\%).

\begin{tabular}{|c|c|c|c|c|c|c|c|c|c|c|c|}
\hline Sample & $\mathrm{SiO}_{2}$ & $\mathrm{Al}_{2} \mathrm{O}_{3}$ & $\mathrm{Fe}_{2} \mathrm{O}_{3}$ & $\mathrm{FeO}$ & $\mathrm{MgO}$ & $\mathrm{CaO}$ & $\mathrm{P}_{2} \mathrm{O}_{5}$ & $\mathrm{Cl}$ & $\mathrm{F}$ & $\mathrm{S}$ & LOI \\
\hline E-2 & 55.4 & 13.2 & 0.9 & 3.2 & 3.2 & 12.3 & 0.14 & 0.05 & 0.04 & 0.03 & 5.6 \\
\hline E-3 & 26.4 & 5.5 & 1.2 & 1.0 & 1.8 & 32.8 & 0.17 & 0.09 & 0.16 & 0.11 & 29.1 \\
\hline E-4 & 59.4 & 15.1 & 1.0 & 3.7 & 3.9 & 7.8 & 0.15 & 0.09 & 0.02 & 0.04 & 2.2 \\
\hline $\mathrm{H}-3$ & 59.7 & 14.3 & 0.9 & 5.5 & 3.8 & 4.6 & 0.18 & 0.02 & 0.10 & 2.02 & 4.0 \\
\hline
\end{tabular}

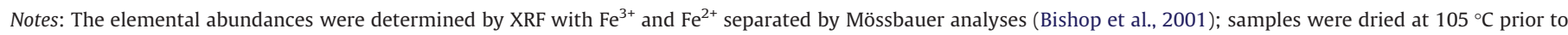
$\mathrm{XRF}$ and loss on ignition (LOI) was determined at $850^{\circ} \mathrm{C}$.

Table 2

Abundance of carbonate and organics and isotopic ratios of $\mathrm{C}, \mathrm{N}$ and $\mathrm{S}$.

\begin{tabular}{|c|c|c|c|c|c|c|c|c|c|}
\hline Sample & $\mathrm{C}_{\mathrm{in}}$ (wt.\%) & $\mathrm{CO}_{2}$ (wt.\%) & $\mathrm{C}_{\text {org }}$ (wt.\%) & $\mathrm{H}_{2} \mathrm{O}$ (wt.\%) & $\delta^{13} \mathrm{C}$ & $\delta^{15} \mathrm{~N}$ & $\delta^{34} \mathrm{~S}_{\mathrm{CRS}}$ & $\delta^{34} \mathrm{~S}_{\mathrm{SS}}$ & Region \\
\hline E-2 & 1.04 & 3.81 & 0.38 & 1.03 & -20.4 & 3.2 & & & Oxic zone \\
\hline E-3 & 6.33 & 23.2 & 1.80 & 3.61 & & & & & Oxic zone \\
\hline E-4 & 0.34 & 1.24 & 0.14 & 0.44 & -19.5 & 3.0 & 0.14 & 5.91 & Oxic zone \\
\hline $\mathrm{H}-3$ & 0.03 & 0.11 & 1.02 & 1.52 & -26.3 & -5.6 & -21.83 & -19.23 & Anoxic zone \\
\hline
\end{tabular}

Notes: The inorganic $\left(\mathrm{C}_{\mathrm{in}}\right)$ and organic $\left(\mathrm{C}_{\mathrm{org}}\right)$ carbon abundances were determined using a LECO RC-412 multiphase determinator (Bishop et al., 2001); $\mathrm{C}$ and $\mathrm{N}$ isotope

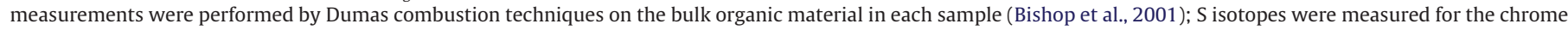
reduced sulfide (CRS) and acid soluble sulfate (SS) components using a Finnigan MAT 252 mass spectrometer (Bishop et al., 2003). 
rate as the flight model. During a nominal EGA run, the pyrolysis oven is heated from ambient temperature to $\sim 1000{ }^{\circ} \mathrm{C}$ at a constant ramp rate, usually $35^{\circ} \mathrm{C} / \mathrm{min}$. As volatiles are released from the sample, they are swept through the gas manifold by helium (He) carrier gas. The gas manifold incorporates flow restrictors to obtain a nominal He pressure of $\sim 35$ mbar inside the pyrolysis oven. The QMS continuously samples the outflow from the oven, scanning over the $m / z$ range of interest. Different types of compounds thermally decompose at different temperatures, so the variation in QMS signal with temperature provides information on the sample's composition. Integration of signal over time for particular compounds enables quantitative estimates of chemical and isotopic abundance.

\subsection{Gas chromatography/mass spectrometry}

The GC/MS (gas chromatography/mass spectrometry) experimental setup includes four subunits: (1) the oven (stepped or ramped heating up to $\sim 1000^{\circ} \mathrm{C}$ ), (2) the cold trap, where evolved volatiles are trapped at temperatures somewhat below $0^{\circ} \mathrm{C}$, (3) the GC unit with a set of different columns for resolving complex mixtures of evolved volatiles into separate components according to their entrainment by the mobile phase (usually He gas) and their interaction with the stationary phase, and (4) a mass spectrometer. The mass spectrometer for SAM is a QMS, while the mass spectrometer planned for MOMA is a 2-D (linear) ion trap that is currently in the design phase. The initial heating step can be enhanced by release of a so-called derivatization agent that transforms potential organic molecules (e.g. acids) into a more volatile form (e.g. esters). The derivatization reagent, by reacting with the labile hydrogen of the molecules present in the soil, improves the detection in two ways. First of all, it will prevent fragile organics from being degraded by the heat of pyrolysis. Secondly, by capping the refractory and/or polar reactive groups of organic molecules that make them challenging to detect by GC/MS, the derivatization process transforms them into more volatile molecules that are more amenable to GC/MS analysis. Both improvements added by the derivatization enable detection of a broader range of organic molecules than pyrolysis alone. Both SAM and MOMA will apply the derivatization technique, although the derivatization agent may not be identical. Here we present two different data sets acquired on Lake Hoare sediments: (a) data acquired using a flight-like configuration with protocols similar to those of SAM GC/MS, and (b) data using a commercial GC/MS set up that is employed as a reference accompanying the MOMA hardware development.

Pyrolysis and derivatization performed in a commercial CDS5100 pyroprobe and a commercial Thermo DSQII GC/MS used an approach similar to that of the SAM experiment. The pyrolysis was performed in an organic-free quartz tube where 10.0, 10.4, 10.9 and $7.5 \mathrm{mg}$ of powdered samples E2, E3, E4 and H3, respectively, were inserted. The quartz tube was packed with glass wool on each side. A blank with no powder was processed under the same conditions before each sample to avoid any contamination from the previous experiment. The sample was pyrolyzed under He carrier gas flow from 250 to $750{ }^{\circ} \mathrm{C}$ at a rate of $250^{\circ} \mathrm{C} / \mathrm{min}$, holding the maximal temperature for $2 \mathrm{~min}$. A hydrocarbon trap (Tenax TA), capturing the molecules pyrolyzed downstream, was set at $50{ }^{\circ} \mathrm{C}$ during pyrolysis. The He flow was then reversed from the trap to the GC inlet while the trap was heated to $300^{\circ} \mathrm{C}$ for 4 min to desorb the organics. GC/MS analysis was achieved on a 30 -m length capillary column Rtx-5 ms similar to one of the SAM GC columns, usually used for separation of $>$ C15 organics. The He flow rate was $1.5 \mathrm{~mL} / \mathrm{min}$ and the temperature range varied from 50 to $320^{\circ} \mathrm{C}$ with a rate of $5^{\circ} \mathrm{C} / \mathrm{min}$ from 50 to $220^{\circ} \mathrm{C}$, then
$10{ }^{\circ} \mathrm{C} / \mathrm{min}$ up to $320^{\circ} \mathrm{C}$. The DSQII scanned from $\mathrm{m} / \mathrm{z} 45$ to 535 , with $m / z 535$ being the upper limit on the SAM instrument.

The derivatization was performed on another similar GC/MS instrument, interfaced with a CDS5100 pyroprobe using quartz boats for sample insertion. Each sample was processed in the following manner: $25 \mathrm{nmol}$ of pyrene and $40 \mathrm{nmol}$ of 3-Fluoro-DL-valine were deposited as a solution in the boat, then dried. Pyrene was the general standard of the experiment used to determine the success of the GC/MS run. 3-Fluoro-DL-Valine was a standard not expected to be present in the sediments under analysis and was utilized to confirm the success of the derivatization reaction. 50.7, 47.1, 50.6 and $51.8 \mathrm{mg}$ of samples E2, E3, E4 and H3, respectively, were combined with $50 \mu \mathrm{L}$ of a mixture of N-methyl-N-(tertbutyldimethylsilyl)trifluoroacetamide (MTBSTFA)/dimethylformamide (DMF) (4:1). The prepared sample was immediately inserted into the pyroprobe and heated to $300^{\circ} \mathrm{C}$ for 3 min under He flow to allow for the one-pot/one-step extraction, derivatization and transfer (Buch et al., 2009) of the organic molecules to the trap, as will be performed on SAM. The ratio and quantities of chemicals are the same as those planned in the SAM derivatization cups. The sample was collected at $50^{\circ} \mathrm{C}$ on a SAM-like trap composed of glass beads, Tenax TA and Carbosieve, then desorbed at $300{ }^{\circ} \mathrm{C}$ for $2 \mathrm{~min}$. The GC/MS runs were performed under a He carrier flow rate of $1.5 \mathrm{~mL} / \mathrm{min}$ on a $30 \mathrm{~m}$-long Rxi-5 capillary column from $50^{\circ} \mathrm{C}$ (held $2 \mathrm{~min}$ ) to $220^{\circ} \mathrm{C}$ with a ramp of $10^{\circ} \mathrm{C} / \mathrm{min}$, then a ramp of $20^{\circ} \mathrm{C} /$ min up to $320^{\circ} \mathrm{C}$. The mass detection ranges were $\mathrm{m} / \mathrm{z} 45$ to 435 in this study.

The other setup that was used as a proxy for the MOMA GC/MS included a Pyrola 2000 unit connected to a Varian 3800 GC with Rtx-20 column $(30 \mathrm{~m} \times 0.25 \mathrm{~mm} \times 0.15 \mu \mathrm{m})$ and a Varian 4000 ion trap MS with internal ionization. The sample was heated by the Pyrola to $900{ }^{\circ} \mathrm{C}$ within $15 \mathrm{~ms}$. Volatiles released during heating and separated by the GC column can be detected within a mass range from 35 to about $500 \mathrm{Da}$. The lower end of that range is set for elimination of abundant light molecules such as nitrogen, oxygen, and water vapor.

\subsection{Laser desorption and ionization}

Powdered samples E2, E4, and H3 were prepared for Laser Desorption and Ionization (LDI) analysis by suspending $12 \mathrm{mg}$ of as-received particulate in $200 \mu \mathrm{L}$ of $18 \mathrm{M} \Omega$ DI water. A $2 \mu \mathrm{L}$ slurry aliquot was pipetted onto highly-polished ground stainless steel multi-target plates, then air dried leaving an opaque spot approximately $4 \mathrm{~mm}$ in diameter. Sample plates were loaded into the target source of either of two laboratory-grade laser mass spectrometers. Organic acids such as those used in matrix-assisted laser desorption/ionization (MALDI) were not added to the sample for these experiments, so that the analysis conditions would be analogous to the "dry" approach used in MOMA. Laser desorption ion trap mass spectrometric analysis was carried out using a Thermo Scientific MALDI LTQ XL unit equipped with a nitrogen (337 nm) commercial laser operated at 20-30 $\mu \mathrm{J}$ energy per pulse and focused to a spot of approximately $100 \mu \mathrm{m}$ diameter. The instrument uses a linear ion trap (LIT) mass analyzer analogous to MOMA. Spectra were obtained in full scan positive ion mode up to a molecular weight of $1500 \mathrm{Da}$ and with an automatic gain control algorithm optimizing the number of laser pulses per scan to maintain signals in a tractable range. Supporting laser desorption time-of-flight (TOF) mass spectrometric analysis was also carried out using a Bruker Autoflex Speed MALDI TOF/TOF equipped with a frequency-tripled Nd:YAG (355 nm) commercial laser operated at slightly higher pulse energies. The Bruker instrument provided a cross-check of the ion trap data; results from the LTQ XL reported here are all consistent with TOF analysis (not further presented here) which was also conducted in positive ion mode. The 
Autoflex was further used to examine the structure of selected compounds through isolation and tandem mass spectrometry (MS/MS), a capability that is included in MOMA.

\section{Results}

\subsection{X-ray diffraction}

XRD patterns are shown in Fig. 2 for samples E2, E4 and H3. Rietveld refinements on these data indicate the presence of several minerals. These results are consistent with previous XRD analyses (Bishop et al., 2001), but give more accurate mineral abundances due to the Rietveld refinements. The oxic region samples are dominated by quartz, feldspar and pyroxene with carbonate and some amphibole. Minerals determined for sample E2 in order of decreasing abundance (with approximate chemical formula): albite (feldspar, $\left.\mathrm{NaAlSi}_{3} \mathrm{O}_{8}\right)$, quartz $\left(\mathrm{SiO}_{2}\right)$, anorthite (feldspar, $[\mathrm{Ca}, \mathrm{Fe}] \mathrm{Al}_{2} \mathrm{Si}_{2} \mathrm{O}_{8}$ ), diopside (pyroxene, $\mathrm{CaMgSi}_{2} \mathrm{O}_{6}$ ), enstatite (pyroxene, $[\mathrm{Mg}, \mathrm{Fe}] \mathrm{SiO}_{3}$ ), calcite (carbonate, $\mathrm{CaCO}_{3}$ ), and tremolite (amphibole, $\mathrm{Ca}_{2} \mathrm{Mg}_{5} \mathrm{Si}_{8} \mathrm{O}_{22}[\mathrm{OH}]_{2}$ ). Sample $\mathrm{E} 4$ contains albite, quartz, anorthite, diopside, enstatite, tremolite, and calcite. The XRD results for the anoxic region sample $\mathrm{H} 3$ gave albite, quartz, anorthite, diopside, enstatite, and pyrite (sulfide, $\mathrm{FeS}_{2}$ ). The pyrite detected here is consistent with the detection of this mineral by Mössbauer spectroscopy with an applied magnetic field (Bishop et al., 2001). The variable feldspar and pyroxene compositions are consistent with previous Raman analyses on these samples (Edwards et al., 2004).

\subsection{VNIR Reflectance Spectroscopy}

The VNIR reflectance spectra of oxic region sediments E2 and E4 exhibit bands near 1 and $2 \mu \mathrm{m}$ characteristic of pyroxene (Fig. 3). The band centers for these two samples occur at 0.93 and 1.90$2.0 \mu \mathrm{m}$, which are consistent with an $\sim 50 / 50 \mathrm{wt} . \%$ mixture of low-Ca and high-Ca pyroxene or a pyroxene having intermediate composition (Cloutis and Gaffey, 1991; Sunshine and Pieters, 1993) due to electronic excitations in Fe-bearing silicates (Burns, 1993). The H3 spectrum has a weaker band near 0.93 and a hint of a band near $2 \mu \mathrm{m}$ as well that are consistent with a mix of pyroxenes. The presence of two pyroxenes is consistent with previous Mössbauer spectroscopy analyses of these samples (Bishop et al., 2001), Raman analyses (Edwards et al., 2004), and the current XRD analyses (Fig. 2). Pyrite has very low reflectance in this region and thus the presence of pyrite in $\mathrm{H} 3$ could be responsible for the lower reflectance observed for this sample.

A strong band near $2.7-3.1 \mu \mathrm{m}$ is present in spectra of all three samples and is due to $\mathrm{H}_{2} \mathrm{O}$ and $\mathrm{OH}$ stretching vibrations in hydrated components (e.g. Eisenberg and Kauzmann, 1969; Farmer, 1974; Bishop et al., 1994). Smaller features at 2.34, 2.53, 3.36, 3.48, and $3.98 \mu \mathrm{m}$ are characteristic of calcite (e.g. Bishop et al., 1996 ) in the oxic region samples. The $3.41 \mu \mathrm{m}$ band and $3.51 \mu \mathrm{m}$ shoulder are due to aliphatic $\mathrm{CH}_{2}$ stretching vibrations (e.g. Bruno and Svoronos, 1989; Gaffey et al., 1993; Bishop et al., 1996). These are most prominent in the anoxic region samples, but notable also in the spectrum of E2. The spectrum of the anoxic region H3 sample also exhibits a doublet feature at 0.67 and $0.70 \mu \mathrm{m}$. This is characteristic of spectral features due to chlorophyll-like pigmenting agents (Hoff and Amesz, 1991). Additional weak bands at 1.40, $1.92,2.20,2.25,2.30$ are attributed to phyllosilicates (e.g. Bishop et al., 2008) and/or amphiboles (Mustard, 1992) in spectra of the oxic region samples. Phyllosilicates were not observed by XRD, which supports the presence of allophane (nanophase aluminosilicate, $\left[\mathrm{Al}_{2} \mathrm{O}_{3}\right]\left[\mathrm{SiO}_{2}\right]_{1.3-2}\left[\mathrm{H}_{2} \mathrm{O}\right]_{2.5-3}$ ) an X-ray amorphous material (van der Gaast et al., 1985) that has VNIR spectral properties similar to Al-smectites (Bishop et al., 2012).
The oxic region sediment spectra (E2 and E4) are compared in Fig. 4 to spectra of calcite, biotite (mica, $\mathrm{K}\left[\mathrm{Mg}, \mathrm{Fe}^{2+}\right]_{3} \mathrm{Al}-$ $\mathrm{Si}_{3} \mathrm{O}_{10}[\mathrm{OH}]_{2}$ ), tremolite and allophane that are likely present based on the XRD results (Fig. 2) and previous analyses of these samples including spectra at longer wavelengths (Bishop et al., 1996, 2001). Biotite spectra exhibit a weak OH stretching overtone band near $1.4 \mu \mathrm{m}$, a band at $2.259 \mu \mathrm{m}$ due to the $\mathrm{OH}$ stretching and bending combination for $\mathrm{OH}$ connected to $\mathrm{Al}$ and either $\mathrm{Fe}$ or $\mathrm{Mg}$ and a band at $2.366 \mu \mathrm{m}$ for the $\mathrm{OH}$ combination band for three $\mathrm{Fe}^{2+}$ cations (Bishop et al., 2008). Raman spectra of some grains matched well with prehnite (Edwards et al., 2004); however, prehnite spectra in this region have bands at 1.48 and $2.35 \mu \mathrm{m}$ that are not observed in the spectra. Amphibole spectra contain a quartet due to the $\mathrm{OH}$ stretching overtone at 1.392$1.396,1.397-1.402,1.403-1.408$, and $1.405-1.416 \mu \mathrm{m}$ plus a doublet due to the $\mathrm{OH}$ stretching and bending combination tones at 2.313-2.337 and 2.384-2.403 $\mu \mathrm{m}$ depending on where the mineral chemistry falls along the tremolite-actinolite line (Mustard, 1992). The E2 and E4 spectra include features at 2.25-2.26, $2.30-2.31$ and a shoulder near $2.37-2.39 \mu \mathrm{m}$ that are consistent with mica (e.g. biotite) and amphibole. These bands shift slightly with mineral chemistry and unique identifications cannot be made using these spectra alone. Mica and amphibole spectra also contain sharp $\mathrm{OH}$ stretching vibrations near $2.7-2.8 \mu \mathrm{m}$ that could be consistent with small features observed in the sediment spectra, although these are observed in the spectrum of $\mathrm{H} 3$ as well as $\mathrm{E} 2$ and E4, and the $\mathrm{H} 3$ spectrum does not contain other features consistent with mica or amphibole.

Allophane spectra include an $\mathrm{OH}$ stretching overtone doublet at 1.37 and $1.41 \mu \mathrm{m}$, a broad water combination band near $1.92 \mu \mathrm{m}$, and an $\mathrm{OH}$ stretching and bending combination band at $2.19 \mu \mathrm{m}$ (Bishop et al., 2012). The shape of the broad bands near 1.93 and $2.20 \mu \mathrm{m}$ in spectra of sample E-2 are more consistent with spectra of allophane than Al-smectites that have an asymmetric water band at $1.91 \mu \mathrm{m}$ and a narrower band near $2.2 \mu \mathrm{m}$. However, the bands are weak and for mixtures like these it is difficult to make a unique mineral assignment. Both Al-smectite and allophane are consistent with the spectral features observed for sample E-2 (Figs. 3 and 4); however, allophane is a more likely component based on the positions of the NIR bands, limited chemical alteration of the samples, and the fact that Al-smectites were not observed by XRD in this study or by Raman in an earlier study (Edwards et al., 2004).

\subsection{Evolved gas analysis}

To demonstrate SAM's capability to detect organic and inorganic materials of interest from this Mars analog environment, EGA analyses were performed with the Lake Hoare samples designated E2, E4, and H3 (Bishop et al., 2001). Sample masses were $14.6 \mathrm{mg}, 12.8 \mathrm{mg}$, and $12.2 \mathrm{mg}$, respectively. Fig. 5a-c illustrates the EGA profiles from these three samples. The results reveal notable differences in volatile content between sediments E2 and E4, from the shallow, oxic part of the lake, and sediment $\mathrm{H} 3$, from the lake's deep, anoxic region. The largest peak for sediment E-2 in Fig. 5a appears to be water released from hydrous minerals at temperatures of $\sim 250-650{ }^{\circ} \mathrm{C}$. However, the $\mathrm{CO}_{2}$ peak released from carbonate minerals between $\sim 500$ and $750{ }^{\circ} \mathrm{C}$ is actually many times larger than the water peak. To enable depiction of all compounds on a single plot, the $\mathrm{CO}_{2}$ trace in Fig. 5a shows the isotopologue at $\mathrm{m} / \mathrm{z} 45$, with peak height $\sim 2.5 \times 10^{5}$ counts $/ \mathrm{s}$, instead of the major peak at $\mathrm{m} / \mathrm{z} 44$, with a peak height $\sim 2.1 \times 10^{7}$ counts/ s. Minor sulfate abundance is indicated by the $\mathrm{small}^{\mathrm{SO}_{2}}$ peak above $\sim 800^{\circ} \mathrm{C}$. Aliphatic hydrocarbons are represented by peaks at $m / z 27$ and 15 . The bulk of these compounds are released between $\sim 300$ and $650^{\circ} \mathrm{C}$, but there is an additional $\mathrm{m} / \mathrm{z} 15$ peak 


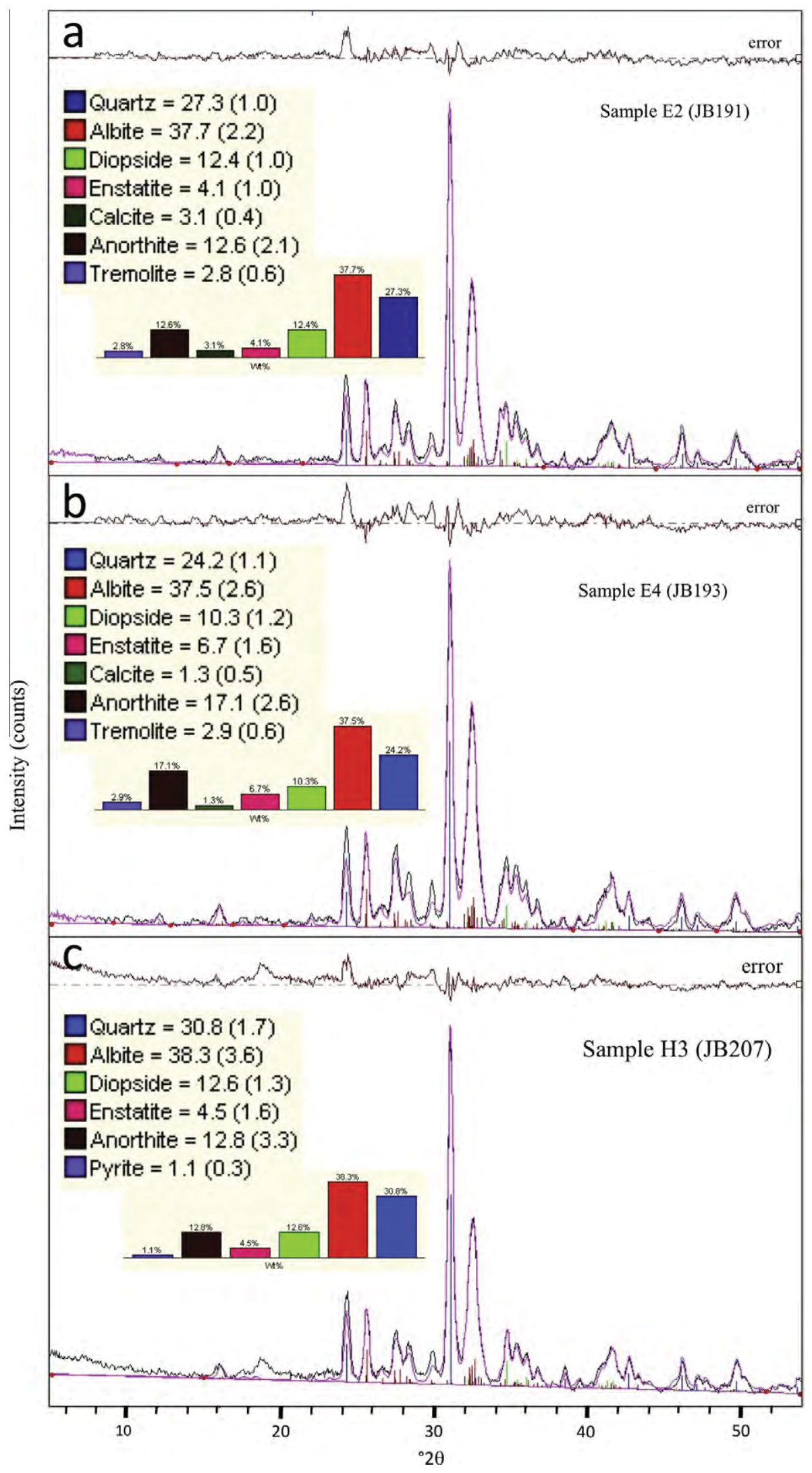

Fig. 2. XRD indicating minerals observed in samples E2, E4 and H3.

coinciding with that of $\mathrm{CO}_{2}$, believed to indicate methane released upon thermal degradation of the carbonate mineral matrix. A much lower abundance of aromatic hydrocarbons, represented by $\mathrm{m} / \mathrm{z} 78$, is seen primarily between $\sim 400$ and $600^{\circ} \mathrm{C}$. 


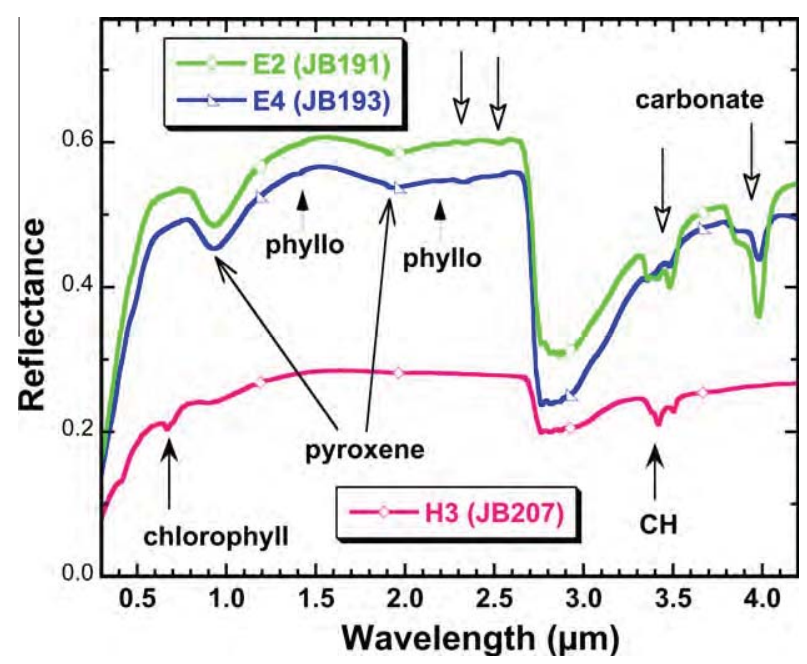

Fig. 3. VNIR Reflectance spectra of Antarctic sediment samples E2, E4 and H3 from 0.3 to $4.4 \mu \mathrm{m}$ showing features due to pyroxene, carbonate, phyllosilicates, hydrocarbons, and chlorophyll.

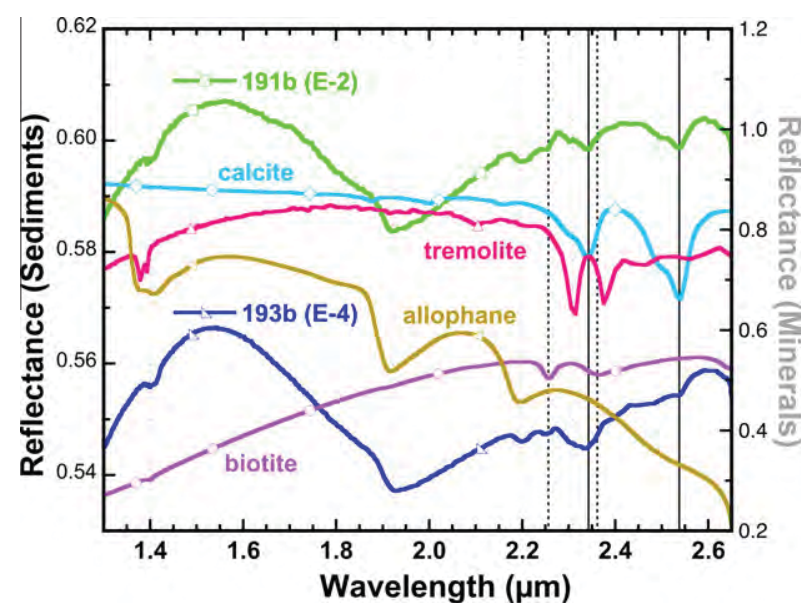

Fig. 4. VNIR reflectance spectra of Antarctic sediments from 1 to $2.65 \mu \mathrm{m}$ compared with mineral spectra from previous studies: calcite (Bishop et al., 2004), biotite (Bishop et al., 2008), allophane (Bishop et al., 2011), and tremolite (USGS spectral library, http://speclab.cr.usgs.gov/, Clark et al., 2007).

The EGA profile of sediment E4 is shown in Fig. 5b. This sample released significantly less water than $\mathrm{E} 2$, over a smaller temperature range. The $\mathrm{CO}_{2}$ peak between $\sim 450$ and $800{ }^{\circ} \mathrm{C}$ again is represented by $m / z 45$, while the major isotopologue at $m / z 44$ has a peak at $\sim 4.6 \times 10^{6}$ counts/s. Bishop et al. (2001) measured the calcite abundance of E2 as 3.81 wt.\% and E4 as 1.24 wt.\%. Assuming that the $\mathrm{EGA} \mathrm{CO}_{2}$ peak in both samples derives solely from carbonate decomposition, normalization of results based on the relative masses of the two samples suggests carbonate content in E2 approximately four times higher than that in E4. In reality, a portion of the $\mathrm{CO}_{2}$ peak probably represents organic material that has been oxidized in the pyrolysis oven. The $m / z 15$ and 27 peaks corresponding to aliphatic hydrocarbons in E2 are approximately three times higher than those of $\mathrm{E} 4$, consistent with a greater contribution of organic material to the $\mathrm{CO}_{2}$ peak in the former sample. The abundance of aromatic hydrocarbons is also notably lower in E4. Both of these observations are in agreement with the relative abundances of organic matter reported for these sediments by Bishop et al. (2001). As for E2, sample E4 also reveals methane released simultaneously with carbonate degradation. The sulfate
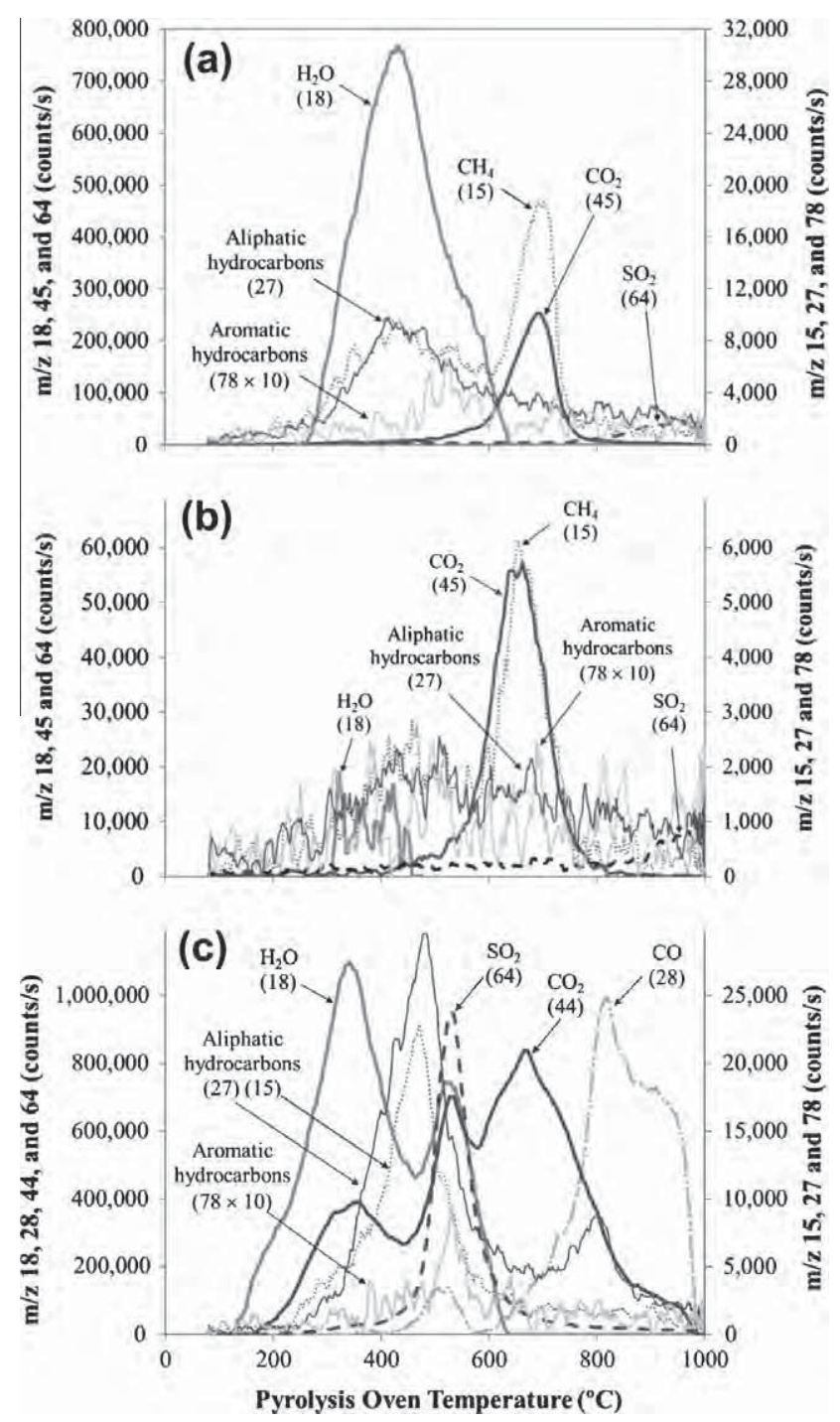

Fig. 5. SAM evolved gas analysis results for samples: (a) E-2, (b) E-4, and (c) H-3. Numbers in parentheses indicate $m / z$ values for the traces shown. See text for discussion.

peak for E4 above $800{ }^{\circ} \mathrm{C}$ is substantially lower than that observed for E2.

Fig. 5c shows EGA results for sediment $\mathrm{H} 3$, which differ substantially from those of E2 and E4. H3 shows the highest abundances of water and organic compounds, both aliphatic and aromatic, of the three samples, a finding that agrees with the water and organic carbon abundances reported by Bishop et al. (2001) and included in Table 2. The largest water release occurs between $\sim 150$ and $450{ }^{\circ} \mathrm{C}$, with a second, smaller peak coinciding with $\mathrm{SO}_{2}$ produced by pyrite degradation at $\sim 450$ and $600{ }^{\circ} \mathrm{C}$. Aliphatic hydrocarbons evolve primarily from $\sim 300$ to $600{ }^{\circ} \mathrm{C}$, with a smaller peak above $\sim 700^{\circ} \mathrm{C}$. The abundance of $\mathrm{CO}_{2}$ released from this sample is significantly lower than those of the previous two samples, with the $\mathrm{m} / \mathrm{z} 44$ peak at carbonate temperatures at $\sim 8.5 \times 10^{5}$ counts/s. This is consistent with the $0.03 \mathrm{wt}$.\% inorganic $\mathrm{C}$ found in sample $\mathrm{H} 3$ attributed to $0.11 \mathrm{wt} . \% \mathrm{CO}_{2}$ as carbonate (Bishop et al., 2001).

The $\mathrm{CO}_{2}$ trace in Fig. $5 \mathrm{c}$ shows two additional peaks at temperatures lower than that of carbonate decomposition, indicating oxidation of organic compounds in the pyrolysis oven. This figure also includes the $m / z 28$ trace, representing primarily CO produced 
from oxidation of organic material. The large $m / z 28$ peak from 600 to $1000{ }^{\circ} \mathrm{C}$ is interpreted to indicate incomplete oxidation of refractory organic compounds to $\mathrm{CO}$ in the absence of sufficient oxygen to produce $\mathrm{CO}_{2}$. The coincident $\mathrm{m} / z 27$ peak indicates the presence of aliphatic hydrocarbon fragments at these temperatures. There is no evidence of methane released upon thermal degradation of the carbonate mineral matrix for sample $\mathrm{H} 3$, perhaps because of very low carbonate abundance for this sample.

\subsection{Gas chromatography/mass spectrometry in a SAM-similar configuration}

\subsubsection{Pyrolysis}

The pyrolysis technique utilized in this study enables extraction of volatile molecules from a sample by heating at high temperature for a short time period. However, since extended heating is needed to extract more complex molecules, only low to mid-molecular weight organic molecules can be detected by this technique. (Note that SAM has considerable flexibility in its possible heating profiles, constrained primarily by the available power, and the method chosen for this study does not reflect limitations of the SAM instrument.) The pyrolysis was performed from 250 to $750{ }^{\circ} \mathrm{C}$ to allow more volatile molecules to be extracted without degradation at mild temperature, and more refractory matter to be extracted at higher temperatures. This range of temperatures is consistent with the EGA results, in which aliphatic hydrocarbons were extracted between 300 and $650^{\circ} \mathrm{C}$ and aromatic hydrocarbons between 400 and $600{ }^{\circ} \mathrm{C}$.

The chromatogram of sample E2 (Fig. 6) displays a large variety and great abundance of organic molecules, which presents some challenges for identification of each individual peak due to coelutions (when multiple compounds exit the column together). Several different aromatic and aliphatic compounds were identified by their mass fragmentation patterns (some major structures shown in Fig. 6). The core of the aromatic compounds are benzene (1 ring), naphthalene and biphenyl (2 rings), phenylnaphthalene, phenanthrene and p-terphenyl ( 3 rings) and pyrene ( 4 rings), these latter groups referred to as poly aromatic hydrocarbons (PAH). All of these key compounds except pyrene also exist under branched forms by adding one or more alkyl, alkene, alcohol or carbonyl groups. There is also a series of compounds produced by repetitive additions of functional groups to a molecule, thus increasing the mass in a systematic manner. Alkyl-benzene is the most relevant example of this, identified throughout the chromatogram from toluene (methylbenzene, C7) to docosylbenzene (C28). This could indicate either a complex chemistry of building blocks up to a significant amount of carbon, or degradation of a higher molecular weight molecule into smaller fragments. The degradation could occur naturally in the sediment or be enhanced by pyrolysis of the sample. Other aromatics (furan ring and derivatives) or PAH-like fluorene and derivatives are also present.

The other representative groups of organic molecules present in sample E2 are alkanes and their corresponding alkenes, which cannot be identified below $\mathrm{C} 13$ (tridecane/tridecene), but can be easily identified with additional $\mathrm{CH}_{2}$ units up to $\mathrm{C} 19$ (nonadecane/nonadecene). Alkane- and alkene-bearing compounds are present in the latest part of the chromatogram (longer time) but cannot be uniquely identified. Nitrogen is revealed primarily as nitrile functional groups and as indole and its derivatives in a few compounds. Additional organic compounds are also present (as indicated by several peaks), but they could not be identified by matching their respective mass fragmentation patterns to the NIST spectral library due to lower abundances and/or background peak interferences.

Sample E4 displays the same qualitative organic content as sample E2, but in a lower abundance. There are no additional compounds in E4 that were not identified in E2. However, there is a significant quantitative difference between these two samples from the GC/MS spectra. E4, which is from a deeper part of the sediment layer of Lake Hoare, shows at least two to three times lower abundance of most organic compounds, consistent with organic contents measured previously (e.g. Bishop et al., 2001). In contrast, the simplest aromatic compound, benzene, is present in E4 at two times the level found in E2. This means that the ratio of benzene (and/or parent molecules degrading to benzene during pyrolysis) to other organic molecules is 4- to 6-times higher in sediment $\mathrm{E} 4$ than in E2. This higher relative abundance might come from degradation of more complex molecules to the most stable one. One can infer that the sediments deposited in this layer are older than the ones at the surface, and underwent conditions that could have led to the partial oxidation or degradation of organic molecules.

Sample E3 is similar to samples E2 and E4, but has elevated levels of organics and calcite (Table 2). It was added to this part of the study for detailed analyses of the organic molecules. The main difference is the presence of a high level of carboxylic acids, which were not detected in samples E2 and E4. The four main carboxylic

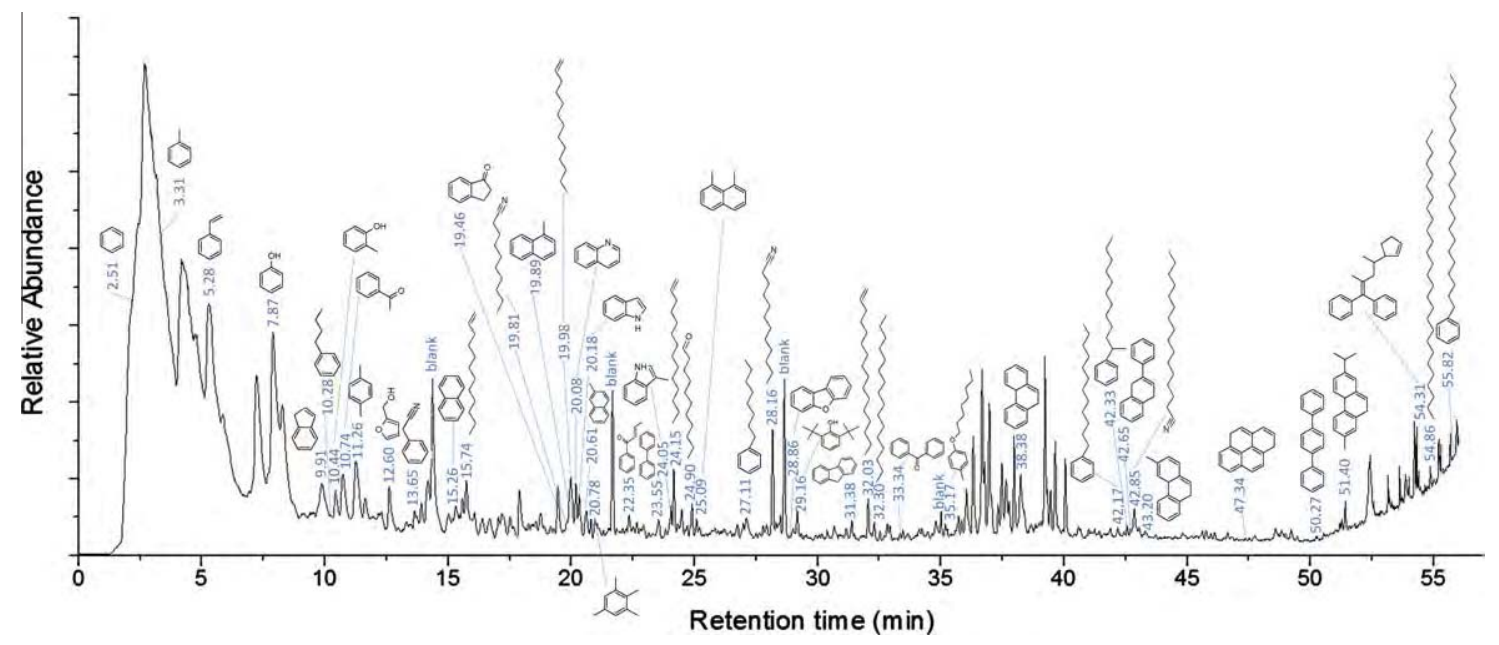

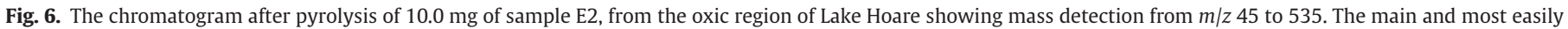

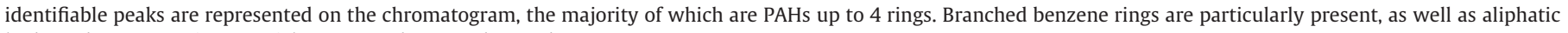
hydrocarbons. Few nitrogen-rich compounds were observed. 
acids are detected by their mass fragment 129 , and are identified as dodecanoic acid (C12), tetradecanoic acid (C14), hexadecanoic acid (C16) and octadecanoic acid (C18). This reveals a series of carboxylic acids with progressive increases in molecular mass equivalent to two $\mathrm{CH}_{2}$ groups, which can be related to life. Indeed, fatty acids, which are biological carboxylic acids and can be degradation products of lipids, exist only with an even number of carbon in living systems, due to their formation pathway. Simply strong detection of fatty acids implies a biological origin of the molecules identified in this oxic region of Lake Hoare.

As demonstrated by EGA and LDI analysis, sample H3 is quite different from the $\mathrm{E}$ series samples from quantitative and qualitative points of view. This result is confirmed by the GC/MS data (Fig. 7). The main compound detected is octathiocane (S8). The detection of hexathiocane (S6) in a lesser amount and of sulfur incorporated into aromatic and aliphatic hydrocarbons is consistent with the presence of pyrite in this sediment (Fig. 2, Bishop et al., 2001). In this sample, the chromatogram displays significantly more nitrogenated compounds than any of the E series, and amines are detected as well. More alcohols, alkanes and alkenes, and methylalkyl derivatives are observed, and more molecules of higher molecular weight and complexity are identifiable (up to $m / z 400$ and above).

\subsubsection{MTBSTFA derivatization}

Chemical derivatization reactions were also performed that enable analysis of fragile or refractory molecules (Rosenbauer et al., 1999). A derivatization solvent transforms less labile polar organic compounds, such as amino acids and carboxylic acids, into volatile tert-butyldimethylsilyl (tBDMS) derivatives that can be separated and identified by GC/MS (Fig. 8).
Chromatograms were obtained after derivatization of $47.1 \mathrm{mg}$ of sample E3 (Fig. 9, top), $51.8 \mathrm{mg}$ of sample H3 (Fig. 9, middle) and a blank (Fig. 9, bottom). The extraction and derivatization of organic molecules was performed as a one-pot/one-step reaction by heating the mixture to $300{ }^{\circ} \mathrm{C}$ for $3 \mathrm{~min}$. In each sample, $50 \mathrm{nmol}$ of standard pyrene and $40 \mathrm{nmol}$ of standard 3-FluoroDL-Valine were used. Those were the only molecules present in the blank before addition of the derivatization reagent $(10 \mu \mathrm{L}$ of MTBSTFA/DMF 4:1 for the blank and $50 \mu \mathrm{L}$ of MTBSTFA/DMF 4:1 for the Lake Hoare samples). The organics were collected on a SAM-like trap (glass beads, Tenax TA and carbosieve) kept at $50{ }^{\circ} \mathrm{C}$, then released to the $\mathrm{GC}$ by heating the trap to $300^{\circ} \mathrm{C}$ for 2 min. The 30-m SAM-like GC column is an Rxi-5. It was heated from 50 (hold $2 \mathrm{~min}$ ) to $220^{\circ} \mathrm{C}$ at a $10^{\circ} \mathrm{C} / \mathrm{min}$ rate, then 220 to $320^{\circ} \mathrm{C}$ at a $20^{\circ} \mathrm{C} / \mathrm{min}$ rate.

In comparison to pyrolysis and other techniques, derivatization of samples E2, E3 and E4 display similar qualitative patterns, with aromatics and aliphatics derivatized. The main challenge for the identification of the mass spectra of the well-separated peaks on the chromatogram is the lack of MTBSTFA-derivatized molecules in the NIST library, which requires a singular knowledge of the derivatized compounds. The molecules identified are of higher molecular mass than molecules usually identified through single pyrolysis, either due to the addition of silyl functional group(s) on the molecules, or because of the extraction and preservation of high molecular weight molecules. A direct detection of amino acids in the samples shows alanine derivatized in sample E3 and proline in sample E2, at low concentration.

Sample H3 displays the same qualitative pattern upon derivatization as the other techniques (Fig. 9), with more derivatized carboxylic acid identified. The main component of the sediment after

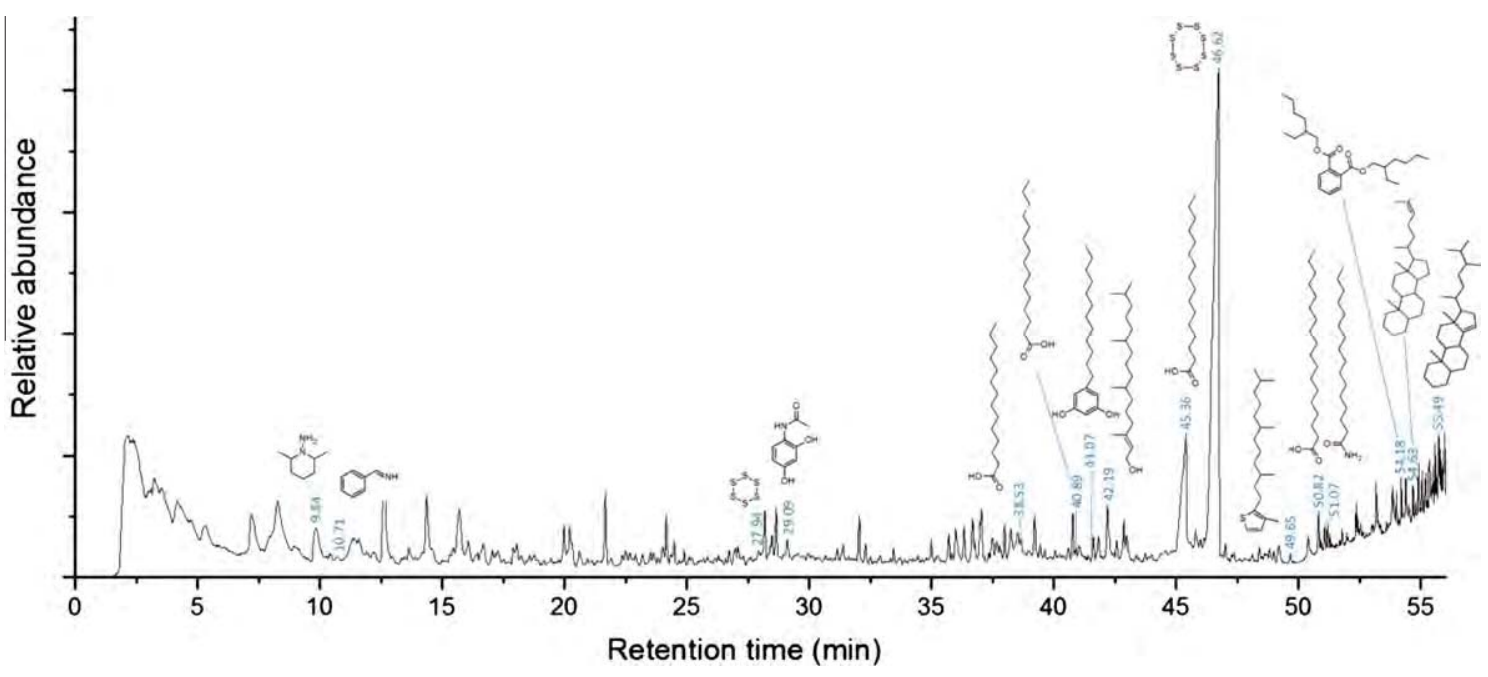

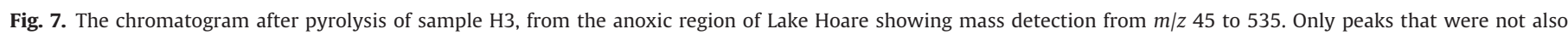
detected in sample E2 are represented here. Sulfur is present, consistent with the detection of pyrite by mineralogical studies. Nitrogen is incorporated into many more

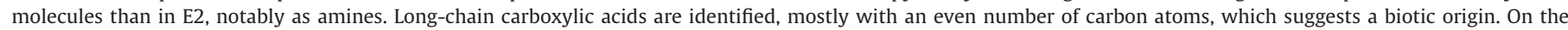
contrary, only a few low molecular weight molecules are present in sample E2 without being seen in sample H3.

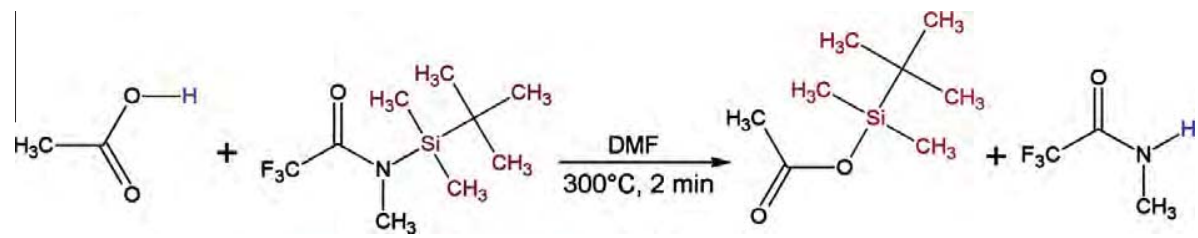

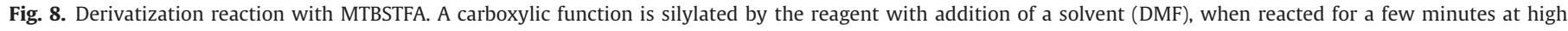
temperature. The labile hydrogen is thus replaced, and the reactivity of the former function is abated. 

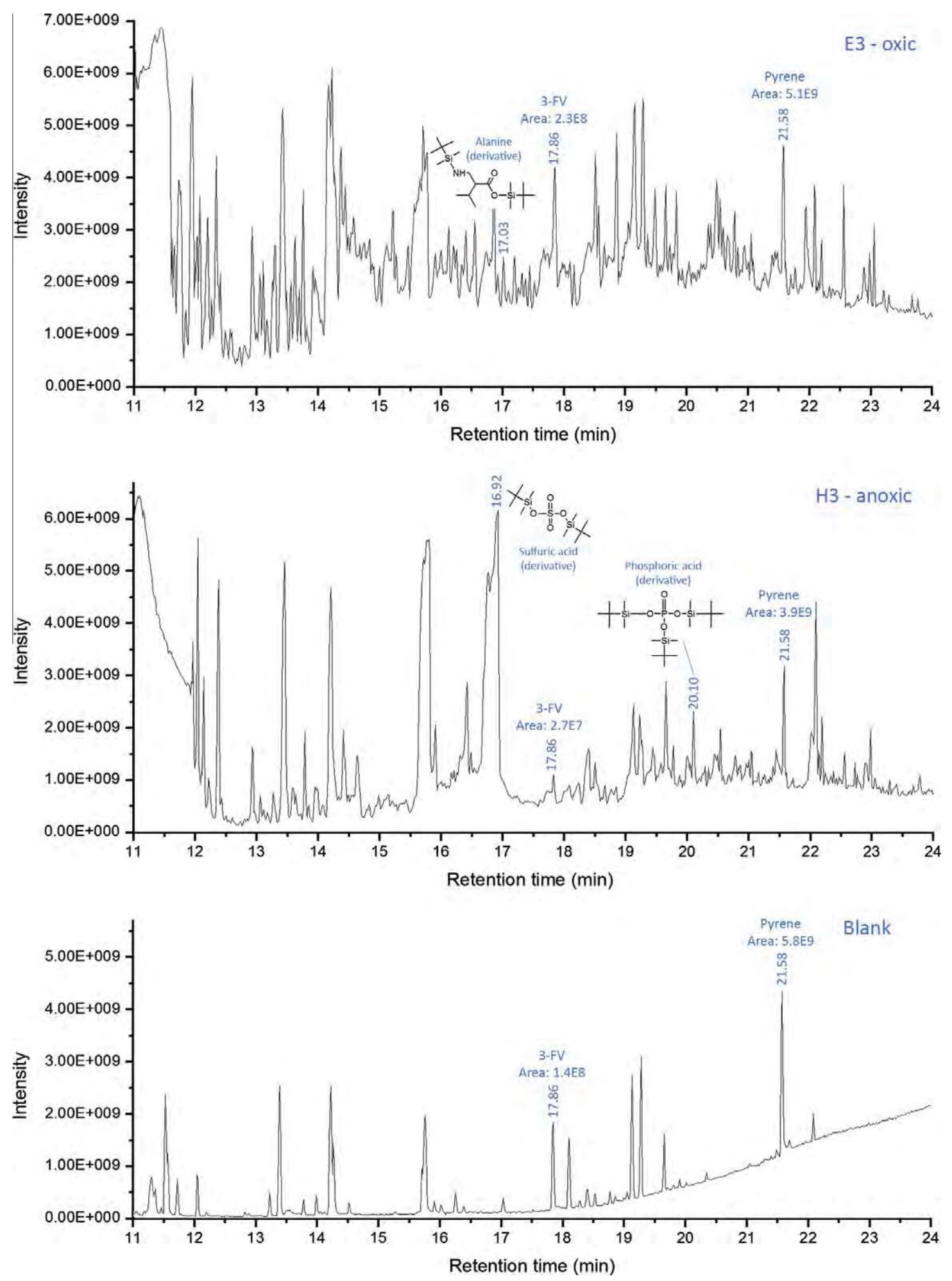

Fig. 9. A portion of the chromatograms obtained after derivatization of sample E3 (top), sample H3 (middle) and a blank (bottom) are represented. The blank run displays many peaks that are attributed to the process rather than the sample. Alanine was found in the E3 oxic region sediment, while phosphoric acid was found in the H3 anoxic region sediment.

derivatization appears to be sulfuric acid derivative (sulfuric acid bis(tert-butyldimethylsilyl)ester), but the most interesting organic molecule detected in this sample from the anoxic part of lake Hoare is a phosphoric acid derivative (Fig. 9). Phosphoric acid is part of the universal DNA composition, along with bases and ribose. The presence of phosphoric acid at a consistent level reveals the biological potential of the sample.
Although sediments E2 and E4 exhibit similar organic matter contents from the pyrolysis study, sample $\mathrm{H} 3$ displays much less organic matter than those oxic region samples. One of the biggest challenges with using MTBSTFA to extract organics from martian analog material is that it reacts readily with active hydrogen, i.e. with bound water (hydrated minerals such as clays) as well as hydroxyl groups in minerals. It may also oxidize in the presence of 
iron oxides (e.g. Rio Tinto sample, Navarro-Gonzalez et al., 2009), and potentially perchlorates (Hecht et al., 2009). These compounds might also hydrolyze or oxidize the targeted organics, leading to their destruction during the extraction and derivatization process, which uses extreme temperatures at which compounds can become oxidizing. This has been suggested to explain the quantitative differences among the four samples studied.

The pyrene quantification, which is similar for each sample, attests that the GC/MS runs responded consistently. However, the 3Fluoro-DL-Valine response demonstrates a yield of derivatization 10 times inferior in $\mathrm{H} 3$ samples compared to E2 and E3 (which were similar to each other), and a yield in sample E4 two times greater than that in E2 and E3. Referring to mineralogy and EGA studies, the $\mathrm{H} 3$ anoxic sample contains pyrite, whose Fe can be readily altered to form iron oxides. Moreover, the EGA results show a higher $\mathrm{H}_{2} \mathrm{O}$ release from hydrated minerals in $\mathrm{H} 3$ compared to the $\mathrm{E}$ samples. Both iron oxides and water can contribute to the deactivation of the MTBSTFA reaction, explaining the low yield of derivatization of the amino acid standard and the low content of derivatized molecules in sample H3. On the other extreme, sample E4 displays saturation for each peak corresponding to the MTBSTFA blank chromatogram. E4 bears fewer hydrated molecules and a lower organic content, which simultaneously could have led to the saturation of the trap/column by too much of the reactive re- agent. MTBSTFA added to samples E2 and E3 yields a smooth chromatogram in between the low (H3) and high (E4) extremes of the other samples, and could have been partially deactivated by the $\mathrm{H}_{2} \mathrm{O}$ present (see EGA results), while still derivatizing a portion of the organic content.

\subsection{GC/MS and LDI as anticipated for the MOMA instrument}

In order to demonstrate the synergy between GC/MS and LDI techniques we present here both GC/MS data acquired by the Pyrola set-up (as described earlier) and LDI data.

The GC/MS data were acquired by pyrolyzing about $3.5 \mathrm{mg}$ of sample at $900{ }^{\circ} \mathrm{C}$. The Total Ion Count (TIC) spectra are presented in Fig. 10. These spectra demonstrate that samples E2 and E4 are similar to each other, but differ significantly from $\mathrm{H} 3$. The spectra of the oxic region sediments (E2 and E4) are dominated by aromatic compounds, while the H3 (anoxic region) spectrum points to significant amounts of aliphatic hydrocarbons (as well as aromatic compounds). In addition, the $\mathrm{H} 3$ spectrum is distinct from the E2 and E4 spectra in that it contains the unambiguous signature of elemental sulfur $\left(\mathrm{S}_{6}\right.$, see peak at $\left.\sim 11.95 \mathrm{~min}\right)$. All three samples attest to rich biological activity with the best bio-preservation in the case of H3. Anoxic conditions (as those prevailing for H3) favor the preservation of sulfur and nitrogen containing compounds
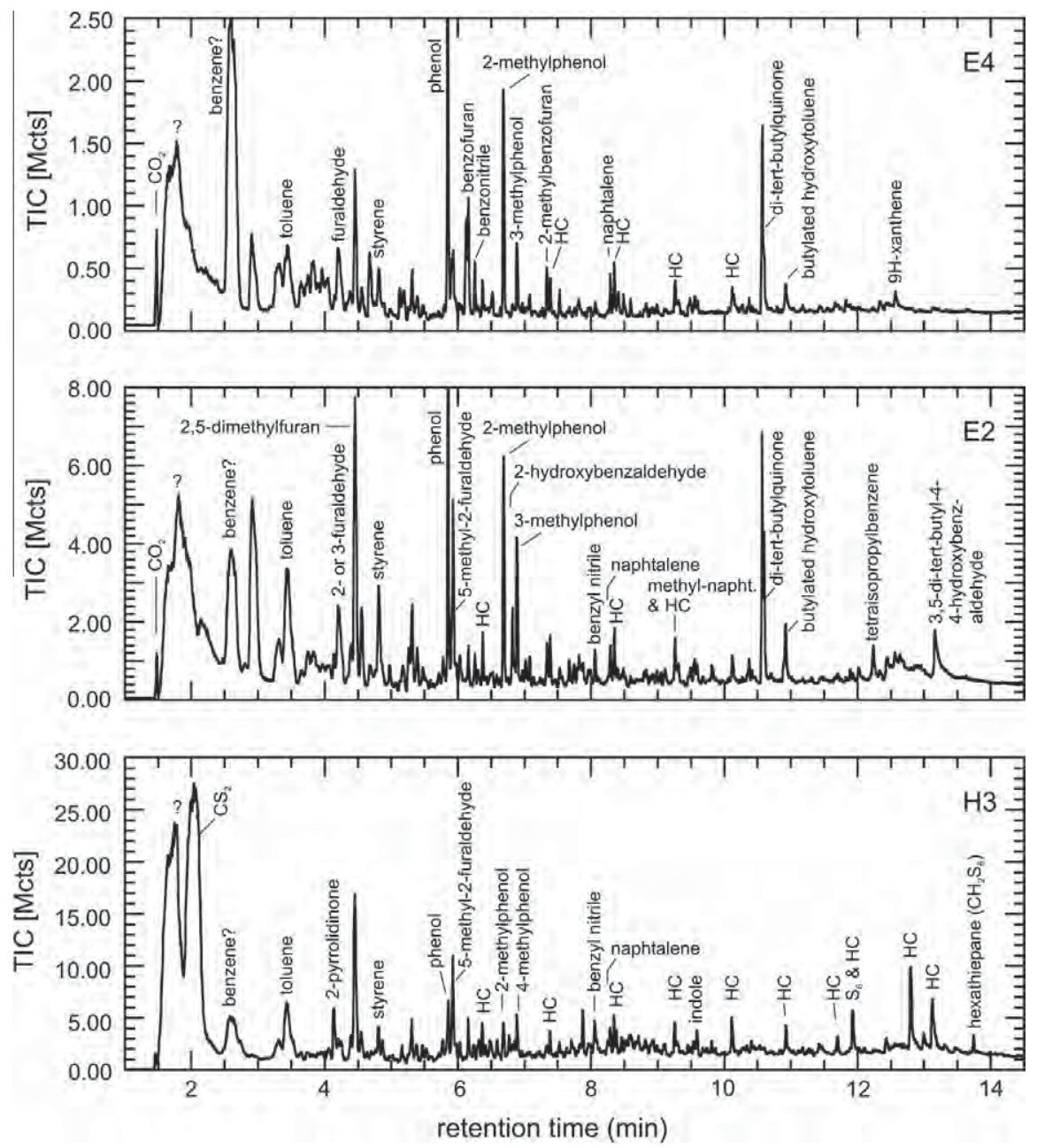

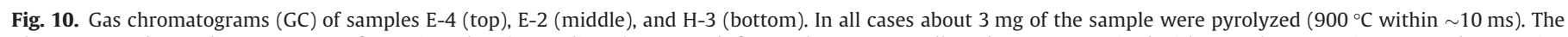

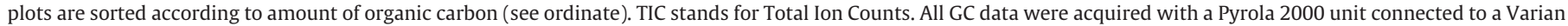

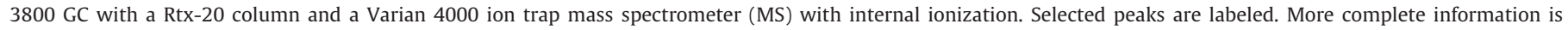
provided in Table S1 (Supplemental Online Material). 
(see imidazole peak at $7.88 \mathrm{~min}$ ), benzyl nitrile, indole, sulfur, and hexathiocane in the H3 spectrum, bottom part of Fig. 10).

We also evaluated the observed organic compounds in terms of potential contaminants. Two components were observed for the oxic region samples that are believed to originate from di-tert-butyl phenols, which are common antioxidants in cosmetic products and lubricants: di-tert-butylquinone (E4 and E2 spectra at 10.6 min) and butylated hydroxytoluene (E4 and E2 spectra at $\sim 10.9$ min). However, the possibility that these are contaminants in the samples is unlikely based on the absence of these peaks in the $\mathrm{H} 3$ spectrum.

The GC/MS analyses of these samples cause major physical/ chemical changes: (1) due to pyrolysis (here $900{ }^{\circ} \mathrm{C}$ ), and (2) due to $70-\mathrm{eV}$ electron ionization in the MS. Thus, it is not straightforward to identify the initial (pre-pyrolysis) organic compounds that were present in the samples as collected. However, nitrogen containing compounds (e.g. $\mathrm{N}$-heterocyclic compounds) may originate from amino acids and proteins. Specifically, benzo nitrile ( $\sim 6.3 \mathrm{~min}$ ) and benzyl nitrile $(\sim 8.1 \mathrm{~min})$ can be derived from phenylalanine. Furthermore, furan and furaldehydes are known to originate from pyrolysis of sugars. Finally, the frequent occurrence of hydrocarbons in all spectra (especially $\mathrm{H} 3$ ) indicates a high concentration of (partially degraded) fatty acids in the samples as collected.

LDI mass spectra of Lake Hoare sediments (Fig. 11) reveal the complex mixture of elemental and molecular composition over a wide mass range (to over $1 \mathrm{kDa}$ ), typical of neat soil LDI data. The elemental mass range below $60 \mathrm{Da}$ is dominated by strong "salt" signals for readily-ionized Na and K. Whereas these everpresent peaks are useful for mass calibration, the intensities are well out of proportion with their concentrations in the samples. Therefore Fig. 11 presents the spectra in the range $100-1100 \mathrm{Da}$, thereby omitting the $\mathrm{Na}$ and $\mathrm{K}$ peaks below $60 \mathrm{Da}$. It is notable that other detected elements including $\mathrm{Mg}, \mathrm{Al}, \mathrm{Ca}, \mathrm{Cr}, \mathrm{Mn}$, and $\mathrm{Fe}$, though not shown here, are consistent with the known composition (Bishop et al., 2001) of these Lake Hoare sediment samples. For example, the LDI signal for $\mathrm{Ca}$ (at $m / z 40$ ) is found to be approximately 3.5 times higher in E2 than in E4, in line with the EGA results for calcite. In addition to detecting elemental peaks, LDI also probes mineral composition to some extent. Oxide and sulfide peaks, such as $\mathrm{TiO}(m / z 64), \mathrm{FeO}(m / z 72), \mathrm{SO}_{3}(m / z 80), \mathrm{FeS}(m / z$ $88)$, and $\mathrm{FeS}_{2}(m / z 120)$, identified by their cation isotopes, are found to be consistent with the major mineralogy in E2, E4, and H3. Such mineral-derived inorganic peak patterns are useful in determining higher molecular weight species that could arise from organics or from inorganic clusters, and in testing hypotheses regarding the correlation of organics and mineral phases.

\section{Discussion}

\subsection{Mineralogy}

Previous Mössbauer spectroscopy measurements of these samples indicate a combination of $\mathrm{Fe}^{2+}$ and $\mathrm{Fe}^{3+}$ minerals (Bishop et al., $2001)$. Although amphibole was not identified previously, the $\mathrm{Fe}^{2+}$ features in the Mössbauer fits presented in Bishop et al. (2001) for these Antarctic samples represent a mixture of pyroxene and amphibole features that may be otherwise indistinguishable due to the similarities between pyroxene and amphibole coordination polyhedra. The $\mathrm{Fe}^{3+}$ component of the Mössbauer spectra are consistent with an $\mathrm{Fe}^{3+}$-bearing clay or iron oxide/hydroxide (Bishop et al., 2001). The VNIR spectra are consistent with an intermediate composition pyroxene or a mixture of two pyroxenes. Two pyroxene compositions and multiple feldspar compositions were identified with Raman spectroscopy (Bishop et al., 2003; Edwards et al.,
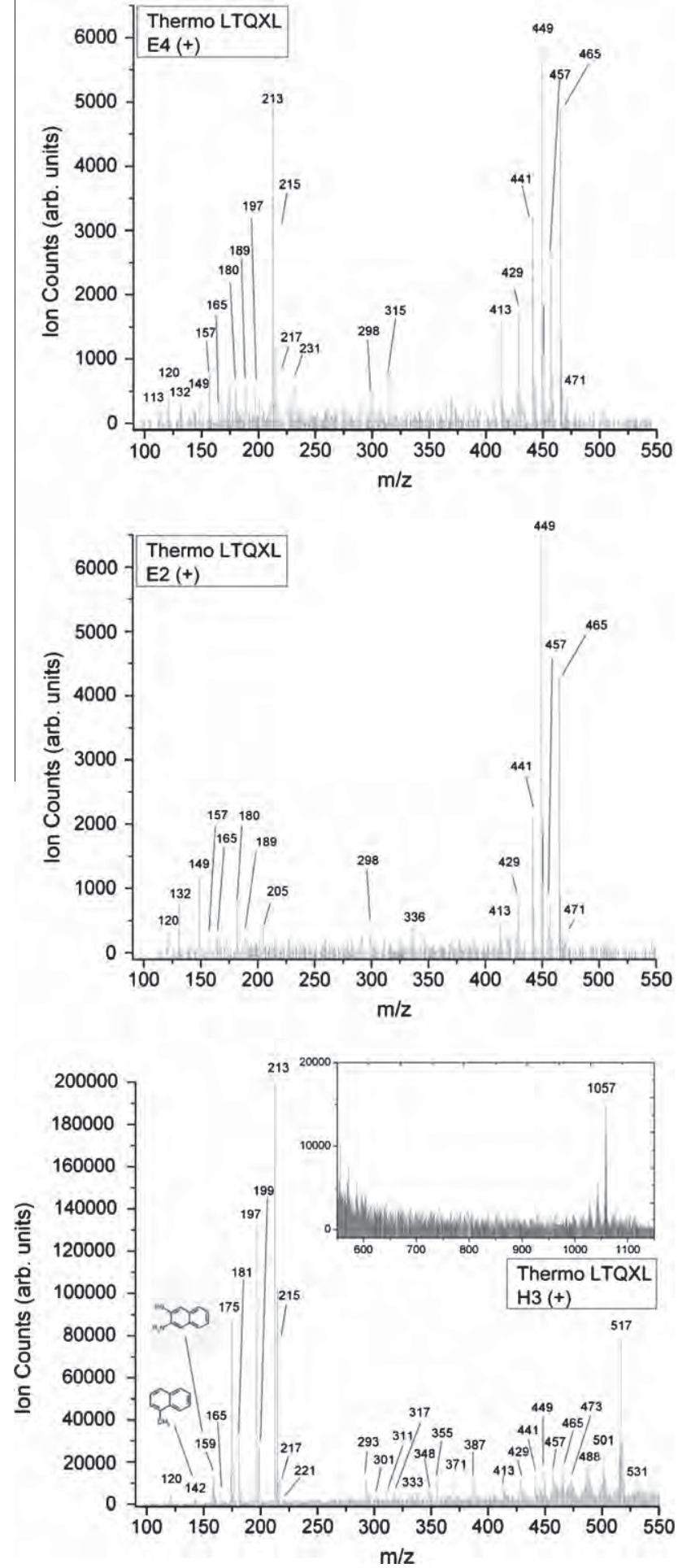

Fig. 11. Positive ion Laser Desorption Ionization (LDI) mass spectra (Thermo-LTQ) of samples E4 (top), E2 (middle), and H3 (bottom) reveal a diverse population of moderate and high molecular weight peaks for all three samples. Similar spectra are observed in each of the E-series samples; in contrast, sample H3 exhibits a more diverse pattern of peaks, with evidence of complex compounds occurring at over $1 \mathrm{kDa}$.

2004). XRD in this study showed diopside, a high-Ca pyroxene and enstatite a low-Ca pyroxene as the two pyroxenes present. The amphibole tremolite identified using XRD in this study may explain the lack of olivine in the samples. The presence of tremolite 
with enstatite and diopside is consistent with the following breakdown reaction:

tremolite + forsterite $=$ enstatite + diopside $+\mathrm{H}_{2} \mathrm{O}$.

The pyrite was found to represent $32 \%$ of the Fe and pyroxene $13 \%$ of the Fe in sample H3 from Mössbauer analyses (Bishop et al., 2001). Pyrite was detected at 1.1 wt.\%, enstatite at 4.5 wt.\% and diopside at 12.6 wt.\% by XRD in the current study for sample H3. Using a ratio of $13 \mathrm{~mol} \mathrm{Fe}$ in pyroxene per $32 \mathrm{~mol} \mathrm{Fe}$ in pyrite, the observed XRD abundances are consistent with $\mathrm{Fe}_{0.02} \mathrm{Ca}_{0.49} \mathrm{Mg}_{0.49}$ $\mathrm{SiO}_{3}$ for diopside and $\mathrm{Fe}_{0.12} \mathrm{Mg}_{0.93} \mathrm{SiO}_{3}$ for enstatite. Although LIBS was not performed in this study, the chemistry of these samples is well documented (Bishop et al., 1996, 2001) and geochemical analyses of the data could be performed in conjunction with mineralogical results from XRD.

Allophane is a short-range ordered aluminosilicate often found in young soils derived from altered volcanic material (e.g. Wada, 1987). Short-range ordered materials are difficult to detect with XRD without special sample handling and processing (e.g. Hillier, 2000), so it is not surprising that allophane or a similar amorphous $\mathrm{Al} /$ Si-rich phase was not detected by XRD. However, the spectral properties of calcite and tremolite that were identified with the CheMin-like instrument resulted in excellent matches with the VNIR spectra of samples E2 and E4. Tremolite had not been previously identified in these samples, but was observed in this study for the oxic region samples. Spectral features due to tremolite near 2.32 and $2.39 \mu \mathrm{m}$ could be detected by CRISM if present on the martian surface.

Calcite abundance was measured at $3.1 \mathrm{wt}$ \% for E2 and $1.3 \mathrm{wt} . \%$ for E4 by XRD (Fig. 2a and b). This is consistent with the stronger NIR carbonate features observed in the E2 spectrum (Fig. 4). Trace amounts of carbonate were also found in H3 by EGA, although calcite was not detected by XRD or NIR spectroscopy for this sample. Previous studies comparing results of various MSL instruments have shown that SAM EGA experiments can detect selected trace minerals in solid samples (Mahaffy et al., 2012) at concentrations below the detection limit of CheMin's XRD mode, which is generally a few percent (Blake et al., 2012).

\subsection{Organic material}

All findings based on EGA and GC/MS spectra are consistent with the depositional environment of these samples (E2 and E4 in the oxic zone, $\mathrm{H} 3$ in the anoxic zone). The 3- to 4-times higher organic content detected in sample $\mathrm{H} 3$ compared to E2 by the pyrolysis-GC/MS experiments is consistent with the previous conclusion of more abundant microbial activity, biological cycling and chlorophyll-like molecule detection in this sample (Bishop et al., 2003). However, the high similarity with the organic molecules found in the E series suggests a biotic origin for the H3 material instead of an abiotic complex chemistry. Furthermore, this supports previous suggestions (Bishop et al., 2003) that many microbes thrived in anoxic zones of the lake and that when conditions changed to oxidize parts of these regions, much of the organic matter was degraded by oxidation in the harsh environment.

EGA showed release of methane during thermal degradation of the carbonate mineral matrix in the oxic region sediments. Biogenic methane has been detected in the anoxic deep water of Lake Hoare (Andersen et al., 1998) and is thought to have contributed to the depleted $\delta^{13} \mathrm{C}$ values observed for the anoxic region sediments from this lake (Bishop et al., 2001). While there is no evidence for methane release from carbonate in $\mathrm{H} 3$, as indicated for samples E2 and E4, methane is probably a component of the aliphatic hydrocarbon peak from $\sim 300$ to $600{ }^{\circ} \mathrm{C}$. The significantly lower carbonate abundance for $\mathrm{H} 3$ and subsequently lower abundance of associated methane could prevent detection of the $\mathrm{m} / \mathrm{z} 15$ peak for this sample by EGA.

The chromatograms following derivatization led to at least three conclusions. (1) The blank displays many peaks which include siloxanes from the trap and the column, products of various reactions in the transfer lines, and degradation products of the derivatization reagent itself. This attests to the high reactivity of MTBSTFA, and the importance of running a blank to subtract from the samples. (2) More peaks (qualitative and quantitative) were observed for sample E3 compared to H3, which is consistent with the relative abundances of organic material (Table 2). (3) Two biologically important molecules were identified using MTBSTFA derivatization: alanine on sample E3 and phosphoric acid on sample H3 (Fig. 9). As components of proteins and DNA, these are important for understanding the biotic origin of the observed organics. MTBSTFA derivatization is a complementary method to pyrolysis-GC/MS that enables detection of complex molecules.

The detection of complex organics using the LDI technique is illustrated by the wide and dense distribution of molecular peaks to over $1 \mathrm{kDa}$, which do not appear in spectra from purely inorganic mineral standards. As the LDI mechanism is most sensitive to nonvolatile organics and is capable of directly detecting the parent structures of certain classes of compounds, it is considered complementary to GC/MS, which focuses on volatile and semi-volatile organics, some of which may be pyrolysis breakdown products of higher molecular weight species. Detailed analysis of organic molecular structure in LDI spectra of these samples is highly involved and will be the subject of a future report; here we focus on a preliminary comparison of the three samples and possible synergies with the GC/MS data obtained here.

LDI spectra include peaks in agreement with some organic assignments by GC/MS, indicative of the useful overlap in analytical sensitivity between these techniques. Examples primarily include ring-containing structures such as phenol, benzene, and naphthalene and some of their methyl- and methoxyl-substituted forms, furaldehydes, pyridine or piperidine, and quinones, among others. The greatest variety and intensity of these common species is found in H3, suggesting a richer structural inventory of organics in this sample compared with E2 or E4. This trend continues in the LDI data to higher molecular weights. Intense signals in $\mathrm{H} 3$ at $\mathrm{m} / \mathrm{z}$ 197,213 , and 215 are likely $\mathrm{Na}$ - and K-adducts of the parent ion at $\mathrm{m} / \mathrm{z} 175$ that will require further analysis to identify. A species unique to $\mathrm{H} 3$, with parent molecular weight $517 \mathrm{Da}$ and its sodiated dimer at $1057 \mathrm{Da}$, was subjected to a preliminary MS/MS analysis, producing fragments with masses of $179 \mathrm{Da}$ and $323 \mathrm{Da}$, and their associated $\mathrm{Na}$ - and K-adducts. This parent mass range is consistent with numerous biomolecules, including phospholipids, however much additional analysis including standardization and additional MS/MS runs will be required before unique assignments can be made.

To a first approximation, a measure of total "complex organic" abundance (including a mixture of aromatic and aliphatic series) can be determined by summing over all peaks above $200 \mathrm{Da}$ and subtracting known contamination and inorganic cluster peaks. While not absolute, the values obtained for each sample may be compared to establish trends. In the LDI spectra the primary contaminants are represented by intense peak groups near $\mathrm{m} / z 393$, 409,449 , and 465 , associated with polymeric residue from exposure to plastic sample storage and handling materials. The integrated signals were then normalized for the overall spectral intensity, which varies from run-to-run depending on automatic adjustment of laser energies. Fig. 12 plots the integrals over GC/ MS TIC spectra (left ordinate) and the sum over organic-related LDI peaks (right ordinate) versus tabulated abundance in organic carbon (Table 2). Thus GC/MS and LDI show an entirely consistent pattern: the anoxic sample H3 exhibits a significantly higher level 


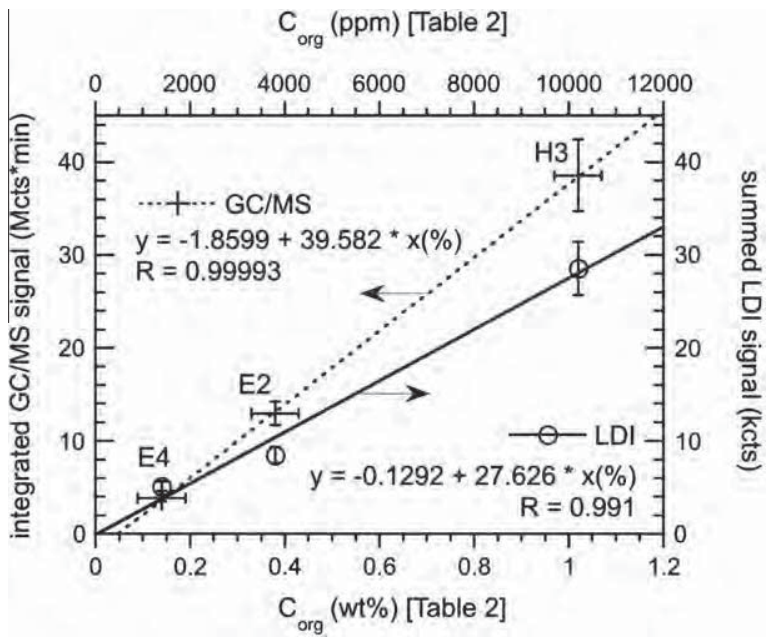

Fig. 12. Integrated GC/MS TIC signals (see Fig. 10) and summed LDI signals (see Fig. 11) plotted versus the abundance in organic carbon (Table 2) for samples E2, E4, and H3. The intersections of the fitted straight lines with the abscissa may be interpreted as detection limits assuming credibility of this 3-point straight-line fit and assuming a fully linear behavior down to the smallest concentrations. With this approach LDI appears to have a significantly better detection limit than GC/MS.

of complex organics than does E2, which is in turn somewhat higher than the level in E4. Such a result is consistent with the GC/MS and LDI spectra reflecting a common population of organic species; those seen in GC/MS may represent pyrolysis breakdown products of the larger structures detectable by LDI.

\subsection{Chlorophyll}

An investigation of the Lake Hoare water found bacteriochlorophyll was present nearly everywhere in the lake, even in the anoxic water below $27 \mathrm{~m}$ depth (Hawes and Schwarz, 1999). Based on cell shape and the occurrence of microbial mats at multiple levels in the lake environment they suggest that the benthic communities are currently metabolically active. The chlorophyll-like bands are strongest for the anoxic region sediments in the upper few $\mathrm{cm}$ (Fig. 3; Bishop et al., 2003); however, it is assumed that bacteriochlorophyll was active in the oxic region mats from the microbial analyses (Hawes and Schwarz, 1999, 2001) and isotopic signatures (Bishop et al., 2003) and that the water level and hence the oxic/ anoxic boundary shifted over time. The chlorophyll-like pigments appear to be less stable in the oxic region lake water.

\section{Summary and applications to Mars}

Overall, the experiments performed here exceeded our expectations in terms of mineralogy and chemistry that can be determined by MSL. The CheMin-like XRD instrument provided mineralogy consistent with previous detailed experiments (Mössbauer, reflectance and Raman spectroscopy, elemental abundances, and XRD) on these samples (Bishop et al., 1996, 2001, 2003) and provided more accurate mineral abundances through Rietveld refinements than previous XRD analyses on these samples. The amphibole mineral tremolite was identified here using the CheMin-like XRD system that was not formerly known to be present in these samples. The NIR spectral properties of tremolite are consistent with weak $\mathrm{OH}$ bands observed in the reflectance spectra. The allophane identified in the NIR spectra is typical of young soils derived from altered volcanic material.

The GC/MS results suggest that the pyrolysis-GC/MS mode of SAM will enable us to make specific organic compound identifications and may contribute toward assessing biotic or abiotic origins of the compounds. Synergistic application of SAM's EGA and GC/MS techniques will allow optimal characterization of organic compounds present in martian samples and any discernible relationships between these compounds and their host minerals. Some of the PAHs detected in the sediments using SAM's EGA and GC/ MS techniques were similar to PAHs found in martian meteorite ALH 84001 (McKay et al., 1996; Clemett et al., 1998). The benzene $(\mathrm{m} / \mathrm{z} 78)$ found in the EGA data could also be a breakdown product of larger PAHs or alkyl-benzene. These experiments provide ground truthing for potential PAH discoveries by SAM at Gale crater.

Another interesting finding was the methane released from the calcite during the EGA experiments. Searching for trapped methane at Gale crater should be possible by EGA as well. This may help to resolve the questions regarding the origin of methane on Mars (e.g. Mumma et al., 2009).

The derivatization experiments highlight the fact that more studies are needed on the reagents and the reactions themselves, both for the MSL and the ExoMars instruments, in order to anticipate most accurately what might be seen on Mars. However, this technique allows for the detection of essential complex molecules of life that are not identifiable by pyrolysis-GC/MS or EGA, such as amino acids and even a component of DNA, phosphoric acid. These results are quite promising for the upcoming investigations of Gale Crater on Mars.

The LDI technique is planned (next to GC/MS) as part of the ExoMars science payload. In general, LDI spectra are difficult to interpret and may be dominated by mineral fragments. However, LDI will be a promising alternative technique for in situ analysis of martian samples due to its higher sensitivity to organics as compared to pyrolysis (EGA, GC/MS) and derivatization experiments.

Finally, it is useful to note that multiple experimental techniques on different rovers can provide complementary information to produce a fuller picture of the geochemical environment. In addition to the techniques analyzed in this study the Raman instrument likely to be part of Exomars (Tarcea et al., 2008; Rull et al., 2011) and the ChemCam LIBS instrument on MSL (Wiens and Maurice, 2011) will contribute towards characterization of both mineralogy and organic composition of martian surface materials. Exploration of the martian surface with integrated instrumentation packages has enormous potential for proving answers to a cross-section of questions about the geologic history and potential for life on Mars.

\section{Acknowledgments}

The authors are grateful to NSF's Office of Polar Programs for sponsoring collection of these samples from the Dry Valleys, to Dr. T. Hiroi for assistance measuring the reflectance spectra, and to Dr. J. Wray for helpful editorial comments. Thanks are also due to NASA's PGG program for supporting Brown University's RELAB facility.

\section{Appendix A. Supplementary material}

Supplementary data associated with this article can be found, in the online version, at http://dx.doi.org/10.1016/j.icarus.2012.05. 014.

\section{References}

Andersen, D.T., McKay, C.P., Wharton Jr., R.A., 1998. Dissolved gases in perennally ice-covered lakes of the McMurdo Dry Valleys, Antarctica. Antarctic Sci. 10, 124-133.

Anderson, D.M., 1981. Some thermodynamic relationships governing the behavior of permafrost and frozen ground. Reports. Planet. Geol. Prog. NASA TM 84211, 292-296. 
Bibring, J.-P. et al., 2005. Mars surface diversity as revealed by the OMEGA/Mars Express observations. Science 307, 1576-1581.

Bish, D.L., Post, J.E., 1993. Quantitative mineralogical analysis using the Rietveld full-pattern fitting method. Am. Mineral. 78, 932-942.

Bishop, J.L., Pieters, C.M., Edwards, J.O., 1994. Infrared spectroscopic analyses on the nature of water in montmorillonite. Clays Clay Miner. 42, 701-715.

Bishop, J.L. et al., 1996. Reflectance spectroscopy and geochemical analyses of Lake Hoare sediments, Antarctica. Geochim. Cosmochim. Acta 60, 765-785.

Bishop, J.L. et al., 2001. Mineralogical and geochemical analyses of Antarctic sediments: A reflectance and Mössbauer spectroscopy study with applications for remote sensing on Mars. Geochim. Cosmochim. Acta 65, 2875-2897.

Bishop, J.L., Anglen, B.L., Pratt, L.M., Edwards, H.G.M., Des Marais, D.J., Doran, P.T., 2003. A spectroscopy and isotope study of sediments from the Antarctic Dry Valleys as analogs for potential paleolakes on Mars. Int. J. Astrobiol. 2, 273-287.

Bishop, J.L., Murad, E., Lane, M.D., Mancinelli, R.L., 2004. Multiple techniques for mineral identification on Mars: A study of hydrothermal rocks as potential analogues for astrobiology sites on Mars. Icarus 169, 331-323.

Bishop, J.L., Lane, M.D., Dyar, M.D., Brown, A.J., 2008. Reflectance and emission spectroscopy study of four groups of phyllosilicates: Smectites, kaoliniteserpentines, chlorites and micas. Clay Miner. 43, 35-54.

Bishop, J.L., Gates, W.P., Makarewicz, H.D., McKeown, N.K., Hiroi, T., 2011. Reflectance spectroscopy of beidellites and their importance for Mars. Clays Clay Miner. 59, 376-397.

Bishop, J.L. et al., 2012. Spectral and hydration properties of allophane and imogolite. Clays Clay Miner., submitted for publication.

Blake, D.F. et al., 2012. Characterization and calibration of the CheMin mineralogical instrument on Mars Science Laboratory. Space Sci. Rev., submitted for publication.

Blecker, S.W., Ippolito, J.A., Barrett, J.E., Wall, D.H., Virginia, R.A., Norvell, K.L., 2006. Phosphorus fractions in soils of Taylor Valley. Soil Sci. Soc. Am. J. 70, 806-815.

Bricklemyer, R.S., Brown, D.J., Barefiled, J.E., Clegg, S.M., 2011. Intact soil core total inorganic, and organic carbon measurements using laser-induced breakdown spectroscopy. Soil Sci. Soc. Am. J. 75, 1006-1018.

Bruno, T.J., Svoronos, P.D.N., 1989. CRC Handbook of Basic Tables for Chemical Analysis. CRC Press, Boca Raton, FL

Buch, A. et al., 2009. Development of a gas chromatography compatible Sample Processing System (SPS) for the in-situ analysis of refractory organic matter in martian soil: Preliminary results. Adv. Space Res. 43, 143-151.

Burns, R.G., 1993. Mineralogical Applications of Crystal Field Theory. Cambridge University Press, Cambridge, UK.

Campbell, I.B., Claridge, G.G.C., 1987. Antarctica: Soils. Weathering Processes and Environment. Elsevier, New York.

Clark, R.N.et al., 2007. USGS digital spectral library splib06a. Digital Data Series 231. US Geological Survey.

Clegg, S.A., Wiens, R.C., Barefield, J., Sklute, E.C., Dyar, M.D., 2009. Quantitative remote laser-induced breakdown spectroscopy by multivariate analysis. Spectrochimica. Acta B 64, 79-88.

Clemett, S.J., Dulay, M.T., Gillette, J.S., Chillier, X.D.F., Mahajan, T.B., Zare, R.N., 1998. Evidence for the extraterrestrial origin of polycyclic aromatic hydrocarbons in the Martian meteorite ALH84001. Faraday Discussions 109, 417-436.

Cloutis, E.A., Gaffey, M.J., 1991. Pyroxene spectroscopy revisited: Spectralcompositional correlations and relationships to geothermometry. J. Geophys. Res. 96, 22809-22826.

Craig, H., Wharton Jr., R.A., McKay, C.P., 1992. Oxygen supersaturation in icecovered Antarctic lakes: Biological versus physical contributions. Science 255, 318-321.

Cremers, D.A., Beddingfield, A., Smithwick, R., Chinni, R.C., Jones, C.R., Beardsley, B. Karch, L., 2012. Monitoring uranium, hydrogen, and lithium and their isotopes using a compact laser-induced breakdown spectroscopy (LIBS) probe and highresolution spectrometer. Appl. Spectrosc. 66, 250-261.

Doran, P.T., Wharton Jr., R.A., Lyons, W.B., 1994. Paleolimnology of the McMurdo Dry Valleys, Antarctica. J. Paleolimnol. 10, 85-114.

Doran, P.T., Wharton Jr., R.A., Des Marais, D., McKay, C.P., 1998. Antarctic paleolake sediments and the search for extinct life on Mars. J. Geophys. Res. 103, 28-48.

Doran, P.T. et al., 2002a. Valley floor climate observations from the McMurdo Dry Valleys, Antarctica, 1986-2000. J. Geophys. Res. 107. http://dx.doi.org/10.1029/ 2001JD002045.

Doran, P.T. et al., 2002b. Antarctic climate cooling and terrestrial ecosystem response. Nature 415, 517-520.

Dyar, M.D., Tucker, J.M., Humphries, S., Clegg, S.M., Wiens, R.C., Lane, M., 2011. Strategies for Mars remote laser-induced breakdown spectroscopy analysis of sulfur in geological samples. Spectrochim. Acta B 66, 39-56.

Edwards, H.G.M., Russell, N.C., Wynn-Williams, D.D., 1997. Fourier Transform Raman spectroscopic and scanning electron microscopic study of cryptoendolithic lichens from Antarctica. J. Raman Spectrosc. 28, 685-690.

Edwards, H.G.M., Jorge Villar, S.E., Bishop, J.L., Bloomfield, M., 2004. Raman spectroscopy of sediments from the Antarctic Dry Valleys: An analog study for exploration of potential paleolakes on Mars. J. Raman Spectrosc. 35, 458462.

Eisenberg, D., Kauzmann, W., 1969. The Structure and Properties of Water. Oxford University Press, New York.

Fairén, A.G. et al., 2010. Astrobiology through the ages of Mars: The study of terrestrial analogues to understand the habitability of Mars. Astrobiology 10, $821-843$.

Farmer, V.C., 1974. The layer silicates. In: Farmer, V.C. (Ed.), The Infrared Spectra of Minerals. The Mineralogical Society, London, pp. 331-363.
Freissinet, C. et al., 2010. Search for evidence of life in space. Analysis of enantiomeric organic molecules by $\mathrm{N}, \mathrm{N}$-dimethylformamide dimethylacetal derivative dependant Gas Chromatography-Mass Spectrometry. J. Chromatogr. A $1217,731-740$.

Gaffey, S.J., McFadden, L.A., Nash, D., Pieters, C.M., 1993. Ultraviolet, visible, and near-infrared reflectance spectroscopy: Laboratory spectra of geologic materials. In: Pieters, C.M., Englert, P.A.J. (Eds.), Remote Geochemical Analysis: Elemental and Mineralogical Composition. Cambridge University Press, Cambridge, pp. 43-77.

Gendrin, A. et al., 2005. Sulfates in martian layered terrains: The OMEGA/Mars Express view. Science 307, 1587-1591.

Gibson, E.K., Wentworth, S.J., McKay, D.S., 1983. Chemical weathering and diagenesis of a cold desert soil from Wright Valley, Antarctica: An analog of martian weathering processes. J. Geophys. Res. 88, A912-A928.

Glavin, D.P., Bada, J.L., 1998. Isolation of amino acids from natural samples using sublimation. Anal. Chem. 70, 3119-3122.

Goesmann, F. et al., 2007. COSAC, the cometary sampling and composition experiment on Philae. Space Sci. Rev. 128, 257-280.

Goetz, W., Steininger, H., Goesmann, F., 2011. Searching for martian Organics with the Mars Organic Molecule Analyzer (MOMA) aboard ExoMars-2018. EPSC-DPS Joint Meeting 2011, Nantes. Abstract \#1281.

Gooseff, M.N., McNight, D.M., Lyons, W.B., Blum, A.E., 2002. Weathering reactions and hyporheic exchange controls on stream water chemistry in a glacial meltwater stream in the McMurdo Dry Valleys. Water Resour. Res. 38. http:// dx.doi.org/10.1029/2001WR000834.

Green, W.J., Angle, M.P., Chave, K.E., 1988. The geochemistry of Antarctic streams and their role in the evolution of four lakes of the McMurdo Dry Valleys. Geochim. Cosmochim. Acta 52, 1265-1274.

Grotzinger, J. et al., 2011. Mars sedimentary geology: Key concepts and outstanding questions. Astrobiology 11, 77-87.

Haskin, L.A., Wang, A., Rockow, K.M., Jolliff, B.L., Korotev, R.L., Viskupic, K.M., 1997. Raman spectroscopy for mineral identification and quantification for in situ planetary surface analysis: A pointcount method. J. Geophys. Res. 102, 1929319306.

Hawes, I., Schwarz, A.-M., 1999. Photosynthesis in an extreme shade environment: Benthic microbial mats from Lake Hoare, a permanently ice-covered Antarctic lake. J. Phycol. 35, 448-459.

Hawes, I., Schwarz, A.-M.J., 2001. Absorption and utilization of irradiance by cyanobacterial mats in two ice-covered Antarctic lake with contrasting light climates. J. Phycol. 37, 5-15.

Hecht, M.H. et al., 2009. Detection of perchlorate and the soluble chemistry of martian soil at the Phoenix Lander site. Science 325, 64-67.

Hillier, S., 2000. Accurate quantitative analysis of clay and other minerals in sandstones by XRD: Comparison of a Rietveld and a reference intensity ratio (RIR) method and the importance of sample preparation. Clay Miner. 35, $291-$ 302.

Hoff, A.J., Amesz, J., 1991. Visible absorption spectroscopy of chlorophylls. In: Scheer, H. (Ed.), Chlorophylls. CRC Press, Inc., Boca Raton, FL, pp. 723-738.

Kolesov, B.A., Tanskaya, J.V., 1996. Raman spectra and cation distribution in the lattice of olivines. Mater. Res. Bull. 31, 1035-1044.

Lasheras, R.J., Bello-Galvez, C., Rodriguez-Celis, E.M., Anzano, J., 2011. Discrimination of organic solid materials by LIBS using methods of correlation and normalized coordinates. J. Hazard. Mater. 192, 704-713.

Mahaffy, P. et al., 2012. The sample analysis at mars investigation and instrument suite. Space Sci. Rev. 1-78.

Mahaney, W.C., Dohm, J., Kapran, B., Hancock, R.G.V., Milner, M.W., 2009. Secondary $\mathrm{Fe}$ and $\mathrm{Al}$ in Antarctic paleosols: Correlation to Mars with prospect for the presence of life. Icarus 203, 320-330.

Marchant, D.R., Head, J.W., 2007. Antarctic Dry Valleys: Microclimate zonation, variable geomorphic processes, and implications for assessing climate change on Mars. Icarus 192, 187-222.

Martin, M.Z., Wullschleger, S.D., Garten, C.T., Palumbo, A.V., 2003. Laser-induced breakdown spectroscopy for the environmental determination of total carbon and nitrogen in soils. Appl. Opt. 42, 2072-2077.

Martin, M.Z., Labbe, N., Andre, N., Wullschleger, S.D., Harris, R.D., Ebinger, M.H., 2010. Novel multivariate analysis for soil carbon measurements using laserinduced breakdown spectroscopy. Soil Sci. Soc. Am. J. 74, 87-93.

McCammon, C., 1995. Mössbauer spectroscopy of minerals. In: Ahrens, T.J. (Ed.), Mineral Physics and Crystallography: A Handbook of Physical Constants. American Geophysical Union, pp. 332-347.

McKay, C.P., Clow, G.D., Wharton Jr., R.A., Squyres, S.W., 1985. Thickness of ice in perennially frozen lakes. Nature $313,561-562$.

McKay, D.S. et al., 1996. Search for past life on Mars: Possible relic biogenic activity in Martian meteorite ALH 84001. Science 273, 924-930.

Milliken, R.E., Grotzinger, J.P., Thomson, B.J., 2010. The paleoclimate of Mars as captured by the stratigraphic record in Gale Crater. Geophys. Res. Lett. 37, L04201. http://dx.doi.org/10.1029/2009GL041870.

Mouri, T., Enami, M., 2008. Raman spectroscopic study of olivine group minerals. J. Mineralog. Petrolog. Sci. 103, 100-104.

Mumma, M.J. et al., 2009. Strong release of methane on Mars in Northern Summer 2003. Science 323, 1041-1045.

Murchie, S.L. et al., 2009a. A synthesis of martian aqueous mineralogy after 1 Mars year of observations from the Mars Reconnaissance Orbiter. J. Geophys. Res. 114. http://dx.doi.org/10.1029/2009JE003342.

Murchie, S.L. et al., 2009b. The Compact Reconnaissance Imaging Spectrometer for Mars investigation and data set from the Mars Reconnaissance Orbiter's 
primary science phase. J. Geophys. Res. 114. http://dx.doi.org/10.1029/ 2009JE003344.

Mustard, J.F., 1992. Chemical analysis of actinolite from reflectance spectra. Am Mineral. 77, 345-358.

Navarro-Gonzalez, R. et al., 2009. The limitations on organic detection in Mars-like soils by thermal volatilization-gas chromatography-MS and their implications for the Viking results. Proc. Natl. Acad. Sci. 103, 16089-16094.

Nedell, S.S., Andersen, D.W., Squyres, S.W., Love, F.G., 1987. Sedimentation in icecovered Lake Hoare, Antarctica. Sedimentology 34, 1093-1106.

Neumann, K., Lyons, W.B., Priscu, J.C., Donahoe, R.J., 2001. $\mathrm{CO}_{2}$ concentrations in perennially ice-covered lakes of Taylor Valley, Antarctica. Biogeochemistry 56 27-50.

Oladipo, O., McCarty, D.K., Hillier, S., Kleeberg, R., 2006. Some successful approaches to quantitative mineral analysis as revealed by the 3rd Reynolds Cup contest. Clays Clay Miner. 54, 748-760.

Poulet, F. et al., 2005. Phyllosilicates on Mars and implications for early martian climate. Nature 438, 623-627.

Rosenbauer, H. et al., 1999. The COSAC experiment on the Lander of the ROSETTA mission. Life Sci. Exobiol. 23, 333-340.

Rull, F., Martinez-Frias, J., Sansano, A., Medina, J., Edwards, H.G.M., 2004 Comparative micro-Raman study of the Nakhla and Vaca Muerta meteorites. J. Raman Spectrosc. 35, 497-503.

Rull, F., Maurice, S., Diaz, E., Tato, C., Pacros, A., Team, R., 2011. The Raman Laser Spectrometer (RLS) on the ExoMars 2018 rover mission. Lunar Planet. Sci. 42. Abstract \#2400.

Salvatore, M.R., Wyatt, M.B., Mustard, J.F., Head, J.W., Marchant, D.R., 2010. Nearinfrared spectral diversity of the Ferrar Dolerite in Beacon Valley, Antarctica: Implications for martian climate and surface compositions. Lunar Planet. Sci. 41. Abstract \#2290.

Sharma, S.K., Lucey, P.G., Ghosh, M., Hubble, H.W., Horton, K.A., 2003. Stand-off Raman spectroscopic detection of minerals on planetary surfaces. Spectrochim. Acta A 59, 2391-2407.

Sharma, S.K. et al., 2011. Raman spectroscopy of low concentration of minerals in basaltic glass analog matric applicable to planetary exploration. Lunar Planet. Sci. 42. Abstract \#1250.

Spaulding, S.A., McKnight, D.M., Stoermer, E.F., Doran, P.T., 1997. Diatoms in sediments of perennially ice-covered Lake Hoare, and implications for interpreting lake history in the McMurdo Dry Valleys of Antarctica. J. Paleolimnol. 17, 403-420.

Spigel, R.H., Priscu, J.C., 1998. Physical limnology of the McMurdo Dry Valley lakes. In: Priscu, J.C. (Ed.), Ecosystem Dynamics in a Polar Desert: The McMurdo Dry Valleys, Antarctica. American Geophysical Union, Washington, DC, pp. 153-187.
Squyres, S.W., Andersen, D.W., Nedell, S.S., Wharton Jr., R.A., 1991. Lake Hoare, Antarctica: Sedimentation through a thick perennial ice cover. Sedimentology 38, 363-379.

Sunshine, J.M., Pieters, C.M., 1993. Estimating modal abundances from the spectra of natural and laboratory pyroxene mixtures using the Modified Gaussian Model. J. Geophys. Res. 98, 9075-9087.

Tamppari, L.K. et al., 2012. Effects of extreme cold and aridity on soils and habitability: McMurdo dry valleys as an analogue for the Mars Phoenix landing Site. Antarctic Science, in press, http://dx.doi.org/10.1017/ S0954102011000800.

Tarcea, N. et al., 2008. Raman LIBS instrument for ExoMars 2013: Calibration and data refining procedures. Int. J. Astrobiol. 7, 76-77.

Tucker, J.M., Dyar, M.D., Schaefer, M.W., Clegg, S., Wiens, R.C., 2010. Optimization of laser-induced breakdown spectroscopy for rapid geochemical analysis. Chem. Geol. 277, 137-148.

van der Gaast, S.J., Wada, K., Wada, S.-I., Kakuto, Y., 1985. Small-angle X-ray powder diffraction, morphology, and structure of allophane and imogolite. Clays Clay Miner. 33, 237-243.

Wada, K., 1987. Minerals formed and mineral formation from volcanic ash by weathering. Chem. Geol. 60, 17-28.

Wentworth, S.J., Gibson, E.K., Velbel, M.A., McKay, D.S., 2005. Antarctic Dry Valleys and indigenous weathering in Mars meteorites: Implications for water and life on Mars. Icarus 174, 383-395.

Wharton Jr., R.A., Parker, B.C., Simmons, G.M., 1983. Distribution, species composition, and morphology of algal mats in Antarctic dry valley lakes. J. Phycol. 22, 355-365.

Wharton Jr., R.A., McKay, C.P., Mancinelli, R.L., Simmons Jr., G.M., 1987. Perennial N supersaturation in an Antarctic lake. Nature 325, 343-345.

Wharton Jr., R.A., McKay, C.P., Mancinelli, R.L., Simmons Jr., G.M., 1989. Early martian environments: The Antarctic lake. Adv. Space Res. 9, 147-153.

Wharton Jr., R.A. Lyons, W.B., Des Marais, D.J., 1993. Stable isotopic biogeochemistry of carbon and nitrogen in a perennially ice-covered Antarctic lake. Chem. Geol. 107, 159-172.

Wiens, R.C., Maurice, S., 2011. The ChemCam instrument suite on the Mars Science Laboratory Rover curiosity: Remote sensing by laser-induced plasmas. Geochem. News $145 . \quad<$ http://www.geochemsoc.org/publications/ geochemicalnews/gn145jun11/chemcaminstrumentsuite.htm>.

Wynn-Williams, D.D., Edwards, H.G.M., 2000. Proximal analysis of regolith habitats and protective biomolecules in situ by laser Raman spectroscopy: Overview of terrestrial Antarctic habitats and Mars analogs. Icarus 144, 486-503. 